\title{
Microstructure and hydrothermal corrosion behavior of NITE-SiC with various sintering additives in LWR coolant environments
}

\author{
Chad M. Parish ${ }^{1}$, Kurt A. Terrani ${ }^{1}$, Young-Jin Kim², Takaaki Koyanagi ${ }^{1}$, and Yutai Katoh ${ }^{1}$ \\ 1. Oak Ridge National Laboratory, Oak Ridge, TN, USA, 37831 \\ 2. GE Global Research Center, Schenectady, NY, 12309, USA \\ *: parishcm@ornl.gov
}

Notice: This manuscript has been authored by UT-Battelle, LLC under Contract No. DE-AC05-000R22725 with the U.S. Department of Energy. The United States Government retains and the publisher, by accepting the article for publication, acknowledges that the United States Government retains a non-exclusive, paid-up, irrevocable, world-wide license to publish or reproduce the published form of this manuscript, or allow others to do so, for United States Government purposes. The Department of Energy will provide public access to these results of federally sponsored research in accordance with the DOE Public Access Plan (http://energy.gov/downloads/doe-publicaccess-plan).

\begin{abstract}
Nano-infiltration and transient eutectic phase (NITE) sintering was developed for fabrication of nuclear grade $\mathrm{SiC}$ composites. We monolithic SiC ceramics using NITE sintering, as candidates for accident-tolerant fuels in light-water reactors (LWRs). In this work, we exposed three different NITE chemistries (yttria-alumina [YA], ceria-zirconia-alumina [CZA], and yttria-zirconia-alumina [YZA]) to autoclave conditions simulating LWR coolant loops. The YZA was most corrosion resistant, followed by CZA, with YA being worst. High-resolution elemental analysis using scanning transmission electron microscopy (STEM) X-ray mapping combined with multivariate statistical analysis (MVSA) datamining helped explain the differences in corrosion. YA-NITE lost all Al from the corroded region and the ytttria reformed into blocky precipitates. The CZA material lost all Al from the corroded area, and the YZA - which suffered the least corrosion -retained some $\mathrm{Al}$ in the corroded region. The results indicate that the YZA-NITE SiC is most resistant to hydrothermal corrosion in the LWR environment.
\end{abstract}

\section{Keywords}

Silicon carbide, liquid phase sintering, sintering aid, hydrothermal corrosion, light water reactor, scanning transmission electron microscopy, multivariate statistical analysis 


\section{Introduction}

Advanced materials have the potential to enhance the performance, reliability, and safety of the current fleet of nuclear power plants as well as many advanced platforms under development today $[1,2]$. A specific example is the development of accident-tolerant fuel and cladding materials to replace the urania/Zr-based alloy fuel system in light water reactors (LWRs) [3]. SiC-based materials are particularly well suited for this purpose since they exhibit exceptional radiation tolerance $[4,5]$ as well as high temperature steam oxidation resistance [6,7]. Accordingly, utilization of SiC-based materials has been proposed both in the form of fuel cladding, as well as fuel pellet itself. The former takes advantage of the well-established SiC fiber/SiC ceramic matrix composite ( $\mathrm{SiC} / \mathrm{SiC}$ ) technology to produce a tough cladding material [8-12]. The specific manifestation of the fuel pellet is the fully-ceramic-microencapsulated fuel (FCM) [13, 14], where tristructural isotropic (TRISO) fuel kernels are embedded inside a sintered SiC matrix. To achieve sufficiently low processing temperatures for the sintered SiC matrix to avoid damaging the TRISO fuel kernels, the nano-infiltration by transient eutectic (NITE) process [15-18] is used. The NITE process is a special type of the conventional liquid phase sintering (LPS) process [19-21] where small amounts (preferably $<10 \mathrm{wt} \%$ and as low as $\sim 3 \mathrm{wt} \%$ ) of oxide additives are added to SiC nanopowder as sintering aids. Utilization of the nanopowders tends to reduce the amount of oxide additives needed for full densification, but may increase the consolidation temperature.[17, 22]. The oxide additives are generally a mixture of alumina, silica and rare earth oxides (usually yttria) blended at eutectic ratios to form a liquid phase during sintering. The NITE sintering process is remarkable in that by utilizing $\mathrm{SiC}$ nanopowder on the order of tens of nanometers in diameter it results in a dense $\mathrm{SiC}$ structure after consolidation at $<1900^{\circ} \mathrm{C}$ in which the $\mathrm{SiC}$ grains (usually $3 \mathrm{C} \beta$ phase) are on the order of a few micrometers. The grain boundaries are wet by thin films $(\sim 2 \mathrm{~nm})$ of the amorphous oxides. Further, at SiC-grain triple-points, there are often larger pockets of the oxides (tens or hundreds of $\mathrm{nm}$ ). These oxide pockets will sometimes be crystalline, and sometimes be amorphous. In previous work on $\mathrm{Y}_{2} \mathrm{O}_{3}-\mathrm{Al}_{2} \mathrm{O}_{3}$ added NITE SiC, for instance, Al-Y-O rich grain boundary films, Al-Y-O triple-points, and Al-O only (Y-deficient) triple-points were observed [23]. Both amorphous and crystalline phases were noted. Even more remarkable is that the transition appeared to result in differential swelling compression of the grain boundaries, resulting in increased strength after irradiation.[24]

For ultimate deployment of SiC-based materials as nuclear fuel or cladding, a number of engineering issues must be explored and quantified $[25,26]$. In this paper, we explore the question of hydrothermal corrosion of the NITE-SiC in LWR coolant environments under normal operating conditions. Due to differences in aqueous parameters such as oxygen activity, corrosion performance is expected to depend on the specific water chemistry in PWR (pressurized water reactor) and BWR (boiling water reactor) coolant environments. Monolithic SiC (such as chemical vapor deposited [CVD]) SiC shows corrosion resistance superior to sintered SiC variants [27-29]. Previously it was shown for high-purity $\mathrm{SiC}$ variants (i.e. CVD-SiC), the corrosion proceeds initially via oxidation of $\mathrm{Si}$ and $\mathrm{C}$ by the water molecule and subsequent dissolution of silica in water where the rate limiting step is the oxidation of $\mathrm{Si}$ [30]. Since the oxidation reaction is the rate limiting step, reducing the oxygen activity in the aqueous environment reduces the rate of material recession [30, 31]. Even for the high purity variants, the grain boundaries, largely free of any impurities, were identified as active corrosion/dissolution sites [32,33]. Grain boundary corrosion was shown to highly accelerate for sintered variants [27], likely due to rapid dissolution of the intergranular sintering additives.

In this study,, the corrosion behavior of the standard NITE-SiC with yttria-alumina sintering additives was examined in three distinct LWR water chemistries. In parallel, a corrosion rate of the 
major sintering additive, alumina, was studied in a separate tests. After observation of the rapid dissolution of alumina in various LWR coolant environments, an effort was undertaken to produce novel NITE-SiC variants with significantly reduced alumina contents. Instead, oxide additives with negligible aqueous corrosion rates were meant to be used as sintering aids. The corrosion behavior and microstructure (before and after corrosion test) of all these NITE variants are reported in this study. Specifically, advanced analytical scanning transmission electron microscope (STEM) techniques were used to produce large area, high-count-rate X-ray maps in order to determine the local nanochemistry in the grains, on the grain boundaries, and at the triple-points. Computational datamining via multivariate statistical analysis (MVSA) of the X-ray maps was used to find correlations between the cations, and MVSA discovered unexpected elemental species.

\section{Procedure}

\section{$\underline{2.1 \text { Fabrication of materials }}$}

The NITE-SiC materials were all produced at ORNL with detailed descriptions of the fabrication procedure in previous publications [17, 22]. Briefly, SiC nanopowder was milled along with oxide additives using $\mathrm{Si}_{3} \mathrm{~N}_{4}$ media in ethanol. Two distinct $\mathrm{SiC}$ nanopowders with 40 and 80 nm average particle size were used with purity of $99 \%$ and $>99 \%$, respectively (supplied by Nanostructured \& Amorphous Materials, Inc., China and Nanomakers, France, respectively). The densification was achieved by hot pressing the powders inside a graphite die under $\mathrm{Ar}$ at $1875^{\circ} \mathrm{C}$ for $1 \mathrm{~h}$ at $10 \mathrm{MPa}$.

This study intended to investigate the effect of various oxide sintering additives on corrosion behavior of NITE-SiC. The reference NITE material was produced using alumina and yttria mixed at the composition corresponding to their lowest temperature eutectic, henceforth referred to as YA-NITE. This is by far the most utilized system for production of sintered SiC with oxide additives. As discussed in the next sections, one of the goals of this study was to eliminate alumina in the mix of sintering additives. Also, it was intended to include zirconia as a sintering additive because zirconia exhibits exceptional radiation stability [34] and negligible dissolution in aqueous environments [35]. The latter is clearly evident from the experience with irradiation of tens of millions of Zr-based alloy cladding tubes in LWR coolant environments where there was no or negligible dissolution of the zirconium oxide film that forms of the surface of these alloys. To ensure radiation stability of zirconia phase, it was intended to stabilize the fluorite structure by addition of yttria or ceria in the mix [36]. The challenge with incorporation of zirconia into the mix of oxide additives without inclusion of alumina is melting it to form the liquid phase. Although silica forms a eutectic with zirconia at temperatures below the maximum processing temperatures of interest, it is a very silica rich liquid [37]. This means that a large amount of silica is needed to melt a small amount of zirconia, and bodes ill with the goal of limiting oxide additives in the system. The binary phase diagrams make it clear that addition of yttria and ceria alone will not result in a liquid phase formation with zirconia [38,39]. Therefore, the adopted strategy was to add only a small amount of alumina compared to the reference YA-NITE specimen.

Table 1 denotes the nominal composition of the powder feedstock (essentially the mixing recipe) as it was initially milled, and the resulting densities. The YA specimen was the reference material with yttria-alumina sintering aids. The CZT series of specimens were small batch $(\sim 10 \mathrm{~g})$ materials prepared and hot-pressed to determine the minimum amount of alumina needed to achieve a dense specimen. As evident from the table, as alumina content increased, the density of the sintered specimen improved significantly. Based on this information, the alumina content of 
$0.45 \mathrm{wt} \%$ was used to prepare large batch $(\sim 100 \mathrm{~g})$ feedstock for plate production of zirconia bearing NITE-SiC specimens. CZA-1, CZA-2, ad YZA plates were produced accordingly to examine the effect of ceria, zirconia, and yttria content on microstructure and hydrothermal corrosion behavior.

Table 1. oxide additive content in the feedstock and the resulting density after hot-pressing for various NITE-SiC specimens.

\begin{tabular}{|l|l|l|l|l|l|}
\hline NITE-SiC & \multicolumn{4}{|l|}{ Feedstock oxide additive content in wt\% } & Density \\
\hline ID & $\mathrm{ZrO}_{2}$ & $\mathrm{Y}_{2} \mathrm{O}_{3}$ & $\mathrm{CeO}_{2}$ & $\mathrm{Al}_{2} \mathrm{O}_{3}$ & $\mathrm{~g} / \mathrm{cm}^{3}$ \\
\hline $\mathrm{YA}$ & & 2.9 & & 3.1 & 3.09 \\
\hline $\mathrm{CZT}-1$ & 3 & & 4 & 0 & 2.51 \\
\hline CZT-2 & 3 & & 4 & 0.25 & 3.03 \\
\hline CZT-3 & 3 & & 4 & 0.375 & 3.11 \\
\hline CZT-4 & 3 & & 4 & 0.5 & 3.24 \\
\hline CZA-1 & 3 & & 4 & 0.45 & 3.21 \\
\hline CZA-2 & 4 & & 2 & 0.45 & 3.21 \\
\hline YZA & 4 & 2 & & 0.45 & 3.24 \\
\hline
\end{tabular}

\subsection{Hydrothermal corrosion testing}

Details of hydrothermal corrosion test conditions have been previously described [30]. The test conditions are summarized in Table 2. Briefly, the tests were conducted in flowing autoclave loops at GE Global Research Center (Schenectady, NY) with strict control of water chemistry. The tests for the different specimens were conducted at different times. All NITE-SiC specimens had a thickness of $\sim 1 \mathrm{~mm}$. Initially, CVD-SiC and the reference YA-NITE were tested. Given the large mass loss rate observed in YA-NITE, the tests were stopped after one and two months for BWR and PWR water chemistry conditions, respectively. Subsequently, polycrystalline alumina specimens (>99.9\% purity) were tested to separately quantify the dissolution rate of this constituent. These tests were conducted for two months and the mass change was measured once a month. Finally, the zirconia bearing NITE-SiC variants (i.e. CZA-1, CZA-2, and YZA) were tested for a duration of five weeks. The mass change data was recorded after two and five weeks for the CZA tests.

After immersion testing, the specimens were removed from the autoclaves at various times and weighed three times each with accuracy of $10 \mu \mathrm{g}$. 
Table 2. Summary of autoclave conditions for immersion tests. PWR: pressurized water reactor. BWR: boiling water reactor. HWC: high water chemistry. NWC: neutral water chemistry.

\begin{tabular}{lcccc} 
Autoclave & Chemistry & $\begin{array}{c}\text { Temperature } \\
\left({ }^{\circ} \mathrm{C}\right)\end{array}$ & $\mathrm{pH}$ & $\begin{array}{c}\text { Pressure } \\
(\mathrm{MPa})\end{array}$ \\
\hline PWR & $3.57 \mathrm{ppm} \mathrm{H}_{2}$ & 330 & 7.2 & 15 \\
BWR-HWC & $0.3 \mathrm{ppm} \mathrm{H}_{2}$ & 290 & 5.6 & 7 \\
BWR-NWC & $1.0 \mathrm{ppm} \mathrm{O}_{2}$ & 290 & 5.6 & 7
\end{tabular}

\section{$\underline{2.3 \text { Microscopy }}$}

After hydrothermal corrosion, samples were mounted, ground, and polished for optical imaging and focused ion beam (FIB) sample preparation for transmission electron microscopy (TEM). Samples were prepared in an FEI Quanta3D DualBeam FIB-SEM (scanning electron microscope) or an FEI Versa DualBeam FIB-SEM, both located at ORNL LAMDA laboratory [40]. FIB preparation used $30 \mathrm{kV}$ down to $5 \mathrm{kV} \mathrm{Ga}$ ions. After FIB, some samples were cleaned with $900 \mathrm{eV}$ $\mathrm{Ar}^{+}$ions in a Fishione Nanomill tool. Samples were taken from approximately the middle of the corroded edge region and approximately the middle of the uncorroded core region for each condition. Samples were FIB-mounted on molybdenum lift-out carriers for TEM, so spurious Mo X-

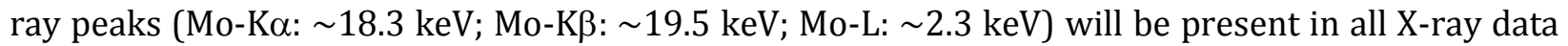
in this paper, and should be ignored. (No X-ray lines of interest overlap with these Mo lines.)

TEM and STEM was performed using an FEI Talos F200X S/TEM instrument [41]. This instrument is uniquely suited to the present problem because, first, it provides a bright electron beam, which can provide high beam currents into a very small region for X-ray mapping with good signal generation. S/TEM imaging is also possible with four imaging detectors simultaneously: bright field (BF), low-angle annular dark field (LAADF), medium angle annular dark field (MAADF), and high-angle annular dark field (HAADF). The BF, LAADF, and MAADF modes are useful for diffraction-contrast imaging of defects, such as grain boundaries, stacking faults, and twins. HAADF image mode shows high-atomic-number regions as bright, and low atomic number regions as dark, and so is useful for imaging phases containing the heavy cations in this study. Second, the F200X instrument has four large silicon-drift detector (SDD) X-ray detectors, providing 0.9 srad of collection angle, and so provides very high speed and high sensitivity X-ray mapping, which is beneficial for interrogating large regions containing small ( $\sim$ wt $\%$ or sub-wt $\%$ ) quantities of features of interest. The 4 SDD chips are windowless and thus have good sensitivity to light elements' soft X-rays, such as C, O, Al, and Si. The F200X STEM was operated at $200 \mathrm{kV}$ accelerating potential.

\subsection{Multivariate statistical analysis of the X-ray data}

A modern STEM like the F200X produces copious X-ray data, which then must be interrogated. Traditional analyst-dependent methods such as generating count maps from X-rays of interest becomes cumbersome and unlikely to yield subtle insights as the datasets become very large [42, 43], so we employed multivariate statistical analysis methods to mine the X-ray spectrum image (SI) datacubes for additional insight and correlations. Specifically, we used the Sandia National Laboratories AXSIA code [44]. Analysis was performed by converting the SIs from the X- 
ray acquisition format into a format readable by AXSIA; this was performed by a custom MATLAB script. AXSIA then read the SI data (typically 4-12 Gb in size), performed optimal scaling for Poisson noise [45, 46], performed a principal component analysis (PCA), followed by matrix rotations and de-scaling to return from the Poisson space to real space. Finally, multivariate curve resolution implemented by alternating least squares (MCR-ALS) under nonnegativity constraints was applied to bring the MVSA results into forms convenient for presentation [47-50].

In practice, from the materials science point of view, MVSA eases interpretation by showing maps of correlated X-ray contributions. What MVSA accomplishes is to find the chemical rank of the sample (i.e., how many independent elemental contributions to the structure), and present these individual contributions in the form of "loading spectra" and "score images". Loading spectra indicate the elements present, and qualitatively, their relative weight. Score images indicate the relative weight of each loading spectrum at each pixel. For instance, Si and C X-ray lines will typically be seen to be present with a strong correlation and will often appear as a single loading spectrum, and the associated score image will show where the $\mathrm{SiC}$ matrix is present.

The SIs were binned in $4 \times 4$ pixel neighborhoods and the spectra truncated to $0.17 \mathrm{keV}$ to $18.16 \mathrm{keV}$ (1800 channels) and binned $2 \times$ in energy for analysis. (There are no close overlaps in energy for the elements of interest in this study.) Data was then returned to its original size after MVSA [51], although some were then re-binned $2 \times 2$ for presentation as figures. MVSA results sometimes show noise components; any components with only noise contributions were removed prior to presentation.

\section{Results}

\section{$\underline{3.1 \text { Mass change behavior }}$}

Figure 1 shows the magnitude of mass loss for YA-NITE conducted during the initial test along with CVD-SiC with the latter previously reported in ref. [30]. In a similar fashion to the behavior for CVD-SiC, the mass loss rate increased with the oxygen activity in the system. However, YA-NITE exhibited accelerated mass loss, roughly two orders of magnitude higher than CVD-SiC after each exposure period. This is consistent with prior reports by Kim et al. [27, 28] on reaction-bonded and sintered $\mathrm{SiC}$ with boron and carbon additives where an increase in mass loss was observed when compared to high-purity CVD-SiC. If one assumed uniform corrosion and a SiC density of $3.2 \mathrm{~g} / \mathrm{cm}^{3}$, every $1 \mathrm{mg} / \mathrm{cm}^{2}$ mass loss is roughly $3.1 \mu \mathrm{m}$ of thickness loss. 


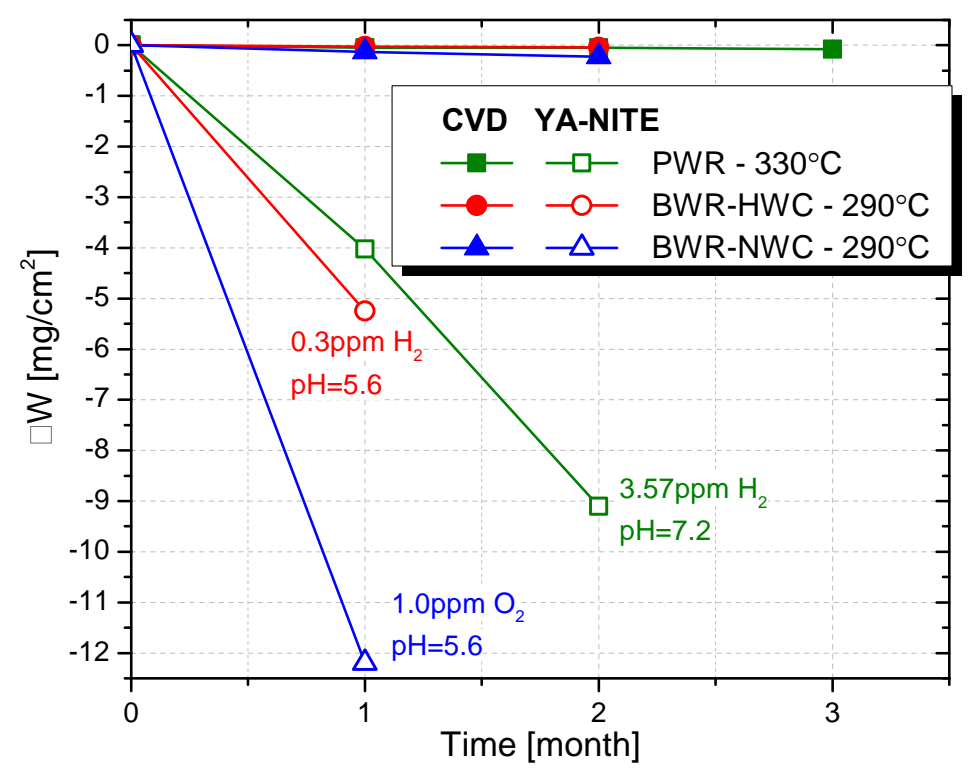

Figure 1. Mass change as a function of time for yttria-alumina NITE-SiC vs. CVD-SiC [30], tested simultaneously under various water chemistry conditions. Figure 1. Mass change as a function of time for yttria-alumina NITE-SiC vs. CVD-SiC [30], tested simultaneously under various water chemistry conditions.

All other mass change data as a function of time, though with limited points available, appeared as linear loss. Therefore, all the results are summarized as linear mass loss rate in Figure 2. Note that no data for CZA-1 is shown in the plot since the entire specimen disappeared after two weeks of immersion testing. The results show that alumina is indeed problematic and exhibits the highest dissolution rate in all cases. The CZA-2-NITE variant perform worse than YA-NITE under BWR water chemistry conditions, indicating adverse effects from ceria addition. The YZA-NITE on the other hand performed much better than the reference YA-NITE under hydrogen water chemistry conditions, namely PWR and BWR-HWC. However, its performance was only marginally better than YA-NITE under BWR-NWC conditions. 


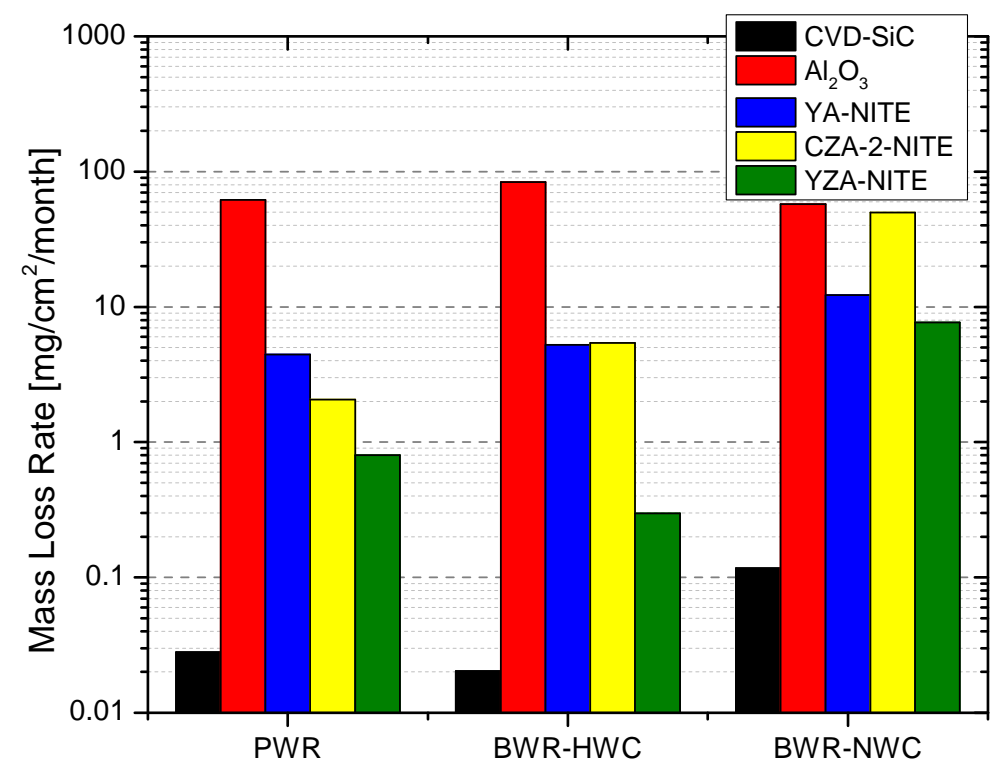

Figure 2. Linear mass loss rate for CVD-SiC, polycrystalline alumina, and NITE-SiC with various sintering additives.

\subsection{Optical microscopy}

Figure 3 shows the optical micrographs of the cross section of various NITE-SiC after immersion testing. In most cases the cross section consists of a bright uncorroded region sandwiched by dark corroded layers on each side. The source of this dark contrast is the presence of porosity in those regions were the sintering additives and portion of the $\mathrm{SiC}$ grains has undergone corrosion and dissolution. This will be shown in a clear manner in the following sections. Note that the dark contrast tends to vary throughout the thickness of the dark layer in some cases, e.g. Fig. 3(a,b). This is likely due to dissolution of different constituents that occurs at different rates. The presence of dissolved oxygen in the BWR-NWC condition appears to present the most corroding environment for all the SiC variants, as shown both in Figs. 2 and 3. The improved corrosion resistance of YZA-NITE is clearly apparent from both mass change data and cross section examinations. The YA- and CZA-2-NITE variants, although not fully dissolved like CZA-1 variant, appear to have undergone severe corrosion after BWR-NWC immersion tests. However, the YZA-NITE variant retained a substantial uncorroded region at the center of test coupon. In a similar fashion, the extent of corrosion for YZA-NITE appears much less after PWR and BWR-HWC test conditions. 

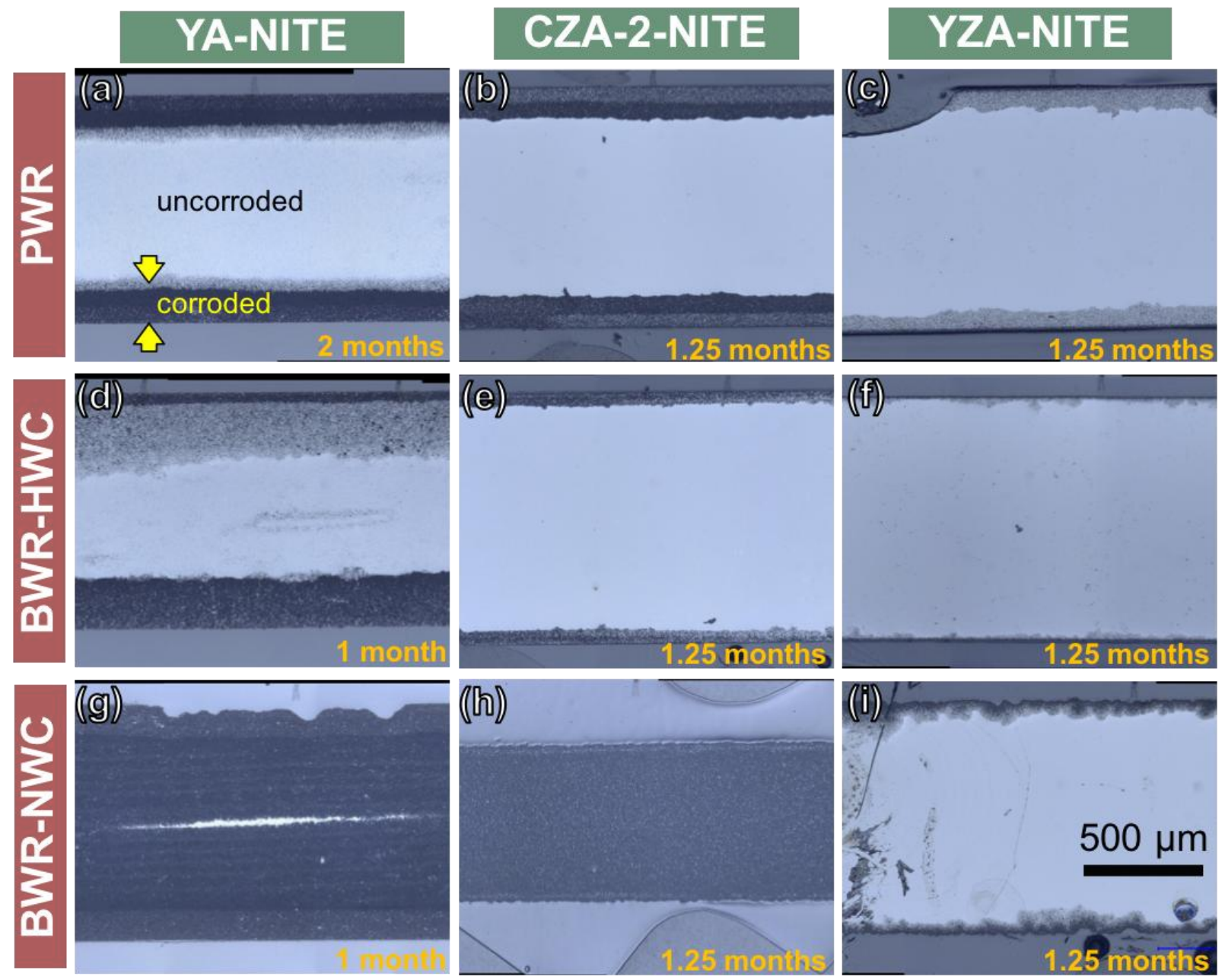

Figure 3: Optical micrographs of the cross section of various NITE-SiC variants after immersion testing.

\section{$\underline{\text { 3.3 Microstructure of uncorroded and PWR-water-corroded NITE-SiC variants }}$}

\subsubsection{YA-NITE: SiC-yttria-alumina}

Prior to corrosion, the YA-NITE structure showed fine $(\sim 1 \mu \mathrm{m})$ grains making up the matrix, and thin layers of yttrium-aluminum oxide along the grain boundaries. Larger pockets of YAl-O were seen at the grain triple-points. The grains are roughly equiaxed and contain faults and twins. Additionally, small SiC grains $(\sim 50-100 \mathrm{~nm})$ were embedded within the oxide at the triplepoint boundaries. This size scale is comparable to the original nanopowder size (See section 2.1). STEM images of the general microstructure are presented in Figure 4, and X-ray maps of the elemental distribution are presented in Figure 5.

Note that in Figure 5, the number of pixels in the map is $800 \times 800$, or $6.4 \times 10^{5}$ pixels total, leading to a data size of $\approx 5 \mathrm{~Gb}$. This enormous dataset size is routine and easy to acquire with an advanced instrument like the FEI Talos used in this study, and importantly to the present context, 
allows very large areas $(4.1 \times 4.1 \mu \mathrm{m}$ in Figure 5) to be mapped with good signal to noise ratio at high resolution $(\sim 5 \mathrm{~nm} /$ pix in Figure 3). Interrogating large areas allows for a better view of the homogeneity, compared to much smaller STEM X-ray maps typical on older instruments, and also allows much finer resolution (i.e., the grain-boundary films) impossible on SEM X-ray mapping.
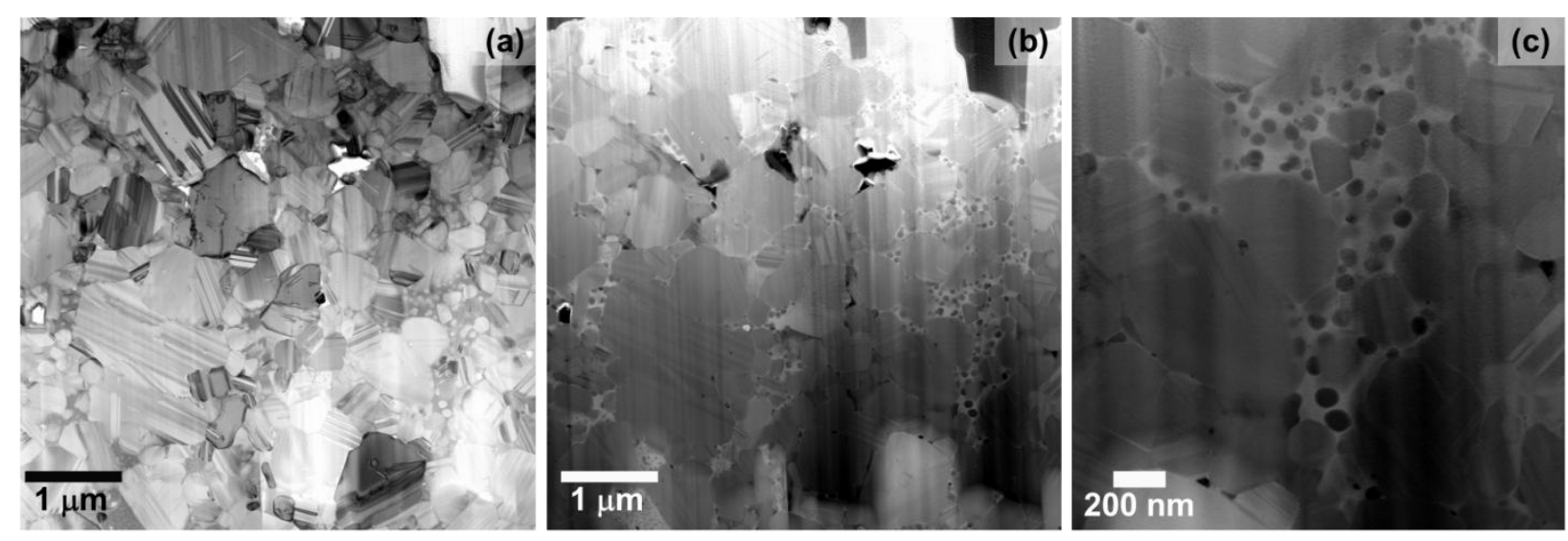

Figure 4: (a) bright field and (b) high-angle annular dark field images of the uncorroded YA-NITE. (c) detail of (b), showing the SiC grains (light) embedded in the oxides (bright).

\section{YA-NITE, Uncorroded region}
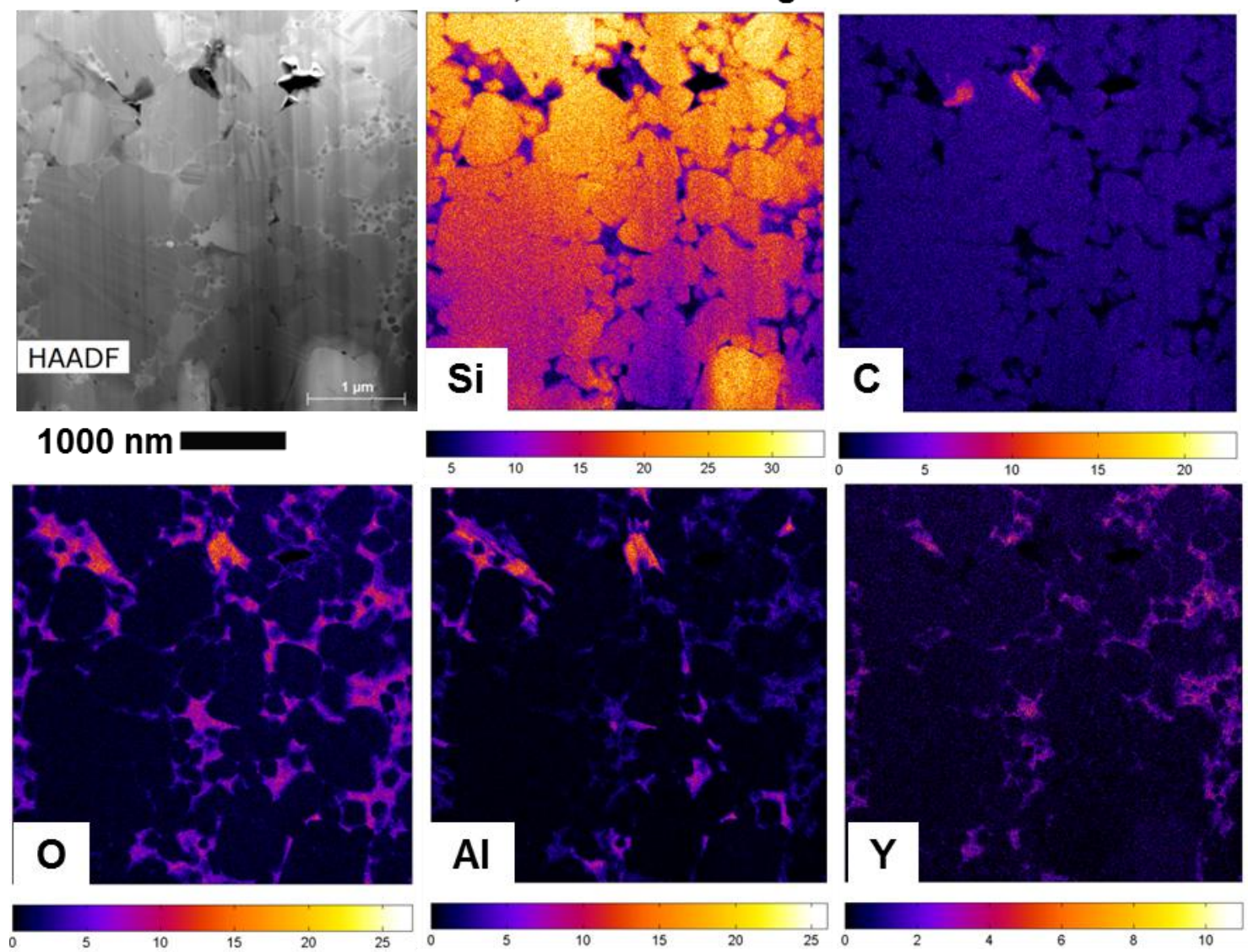
Figure 5: Low-magnification X-ray maps of the uncorroded YA-NITE region. Color bars are raw counts in the named $X$-ray line; all lines are the integrated $K$ series, except for $Y$, which is $K \alpha$.

The Al-O-rich and Y-O-rich features in the YA-NITE, as seen in Figure 3, do not coincide perfectly, indicating that phase separation toward the expected phases, namely alumina and YAG, after cooling from the temperature at or above the eutectic temperature did indeed occur. For such a large dataset $\left(800 \times 800\right.$ pixels, and at 2048 channels at each pixel in the SI, $\approx 1.3 \times 10^{9}$ data elements), the only way to interrogate the data and find the correlations and anti-correlations is attack by computational datamining. MVSA (as described in Section 2.3) found 8 non-noise components in this dataset. The first component (Figure 6a) indicates the $\mathrm{Si}$ in the $\mathrm{SiC}$ matrix. A few pockets of nearly-pure $\mathrm{C}$ are also found, as well as the $\mathrm{C}$ in the $\mathrm{SiC}$ matrix, Figure $6 \mathrm{~b}$. The $\mathrm{Al}, \mathrm{Y}$, and $\mathrm{O}$ elements were broken out into three separate MVSA components (Figure 6c, 6d, and 6e): separation into different components is a sure sign that the spatial distributions of these three elements are different. Had a single phase of constant Y:Al:O ratio been present, a single MVSA component would have been found showing the relative weights of the three sets of X-ray lines in the loading spectrum. Importantly, the grain-boundary films are seen to be dominated by the Y-O mixture.

A small Fe-Cr precipitate was also found as an MVSA component, Figure 6f, likely introduced during powder preparation. This is probably a contaminant introduced during ball milling. This indicates another major advantage of MVSA of these large SI datasets: unexpected features which the analyst was not specifically seeking will be presented, helping ensure no significant features are missed.
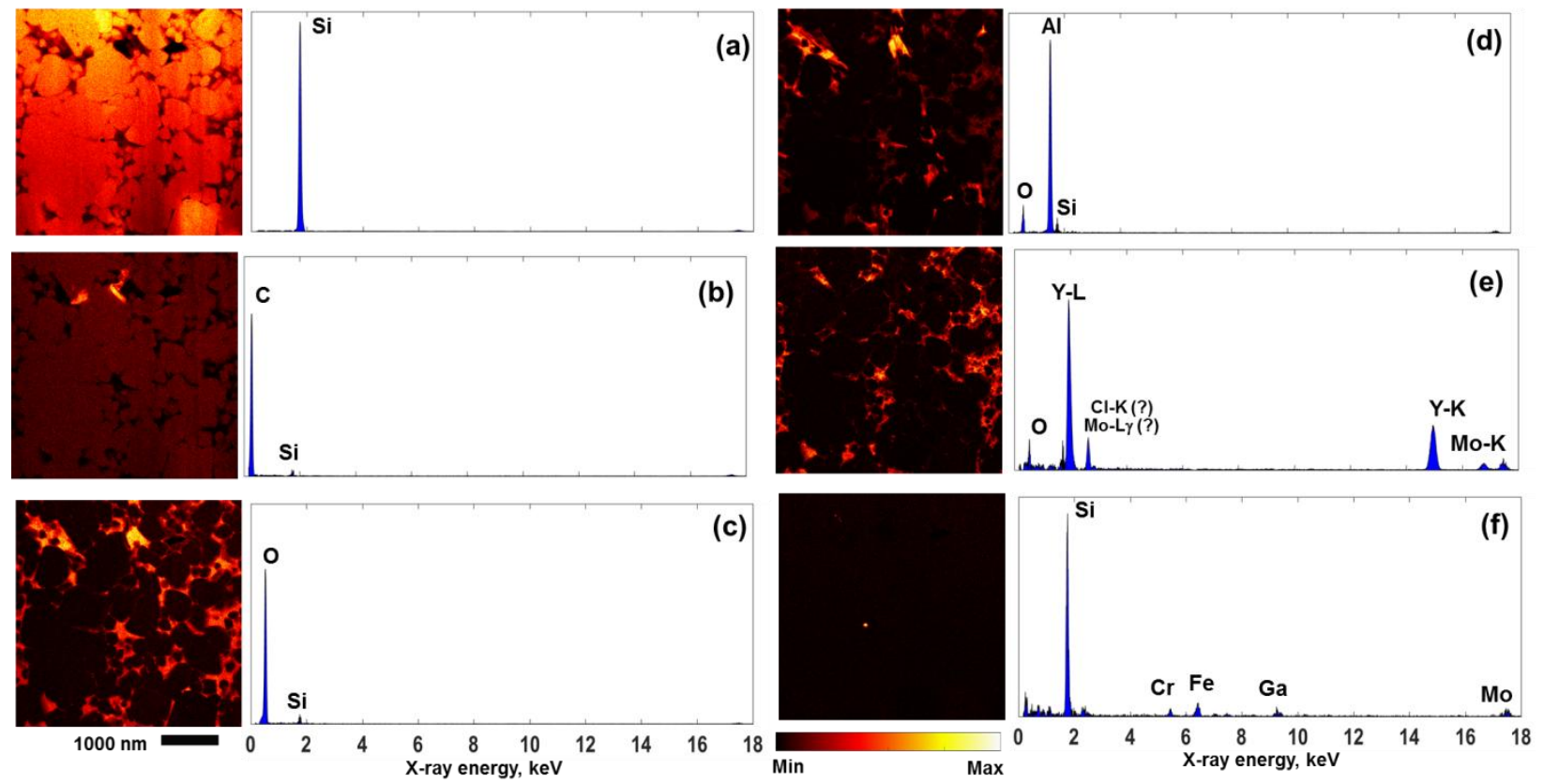

Figure 6: Score images and loading spectra from the MVSA analysis of the uncorroded YA-NITE specimen.

Although regions of mixed Y-Al-O are often observed, there are also many regions of Al-O with no Y present. The grain boundaries are predominantly the mixed Y-Al-O material, and the grain triple-points predominantly the $\mathrm{Al}-\mathrm{O}$ material. The triple-points containing the small $\mathrm{SiC}$ grains are mostly the $\mathrm{Y}-\mathrm{Al}-\mathrm{O}$ material. This is most easily seen by producing a false-color overlay of 
the non-matrix MVSA components (Figure 7). Coloring the 0-component blue, the Y component red, and the $\mathrm{Al}$ component yellow, the structure resolves into cyan (yellow+blue: $\mathrm{Al}+\mathrm{O}$ ) and purple (red+blue+yellow: $\mathrm{Y}+\mathrm{O}+\mathrm{Al}$ ) regions. A single green particle in Figure 7 is the $\mathrm{Fe}-\mathrm{Cr}$ contaminant.

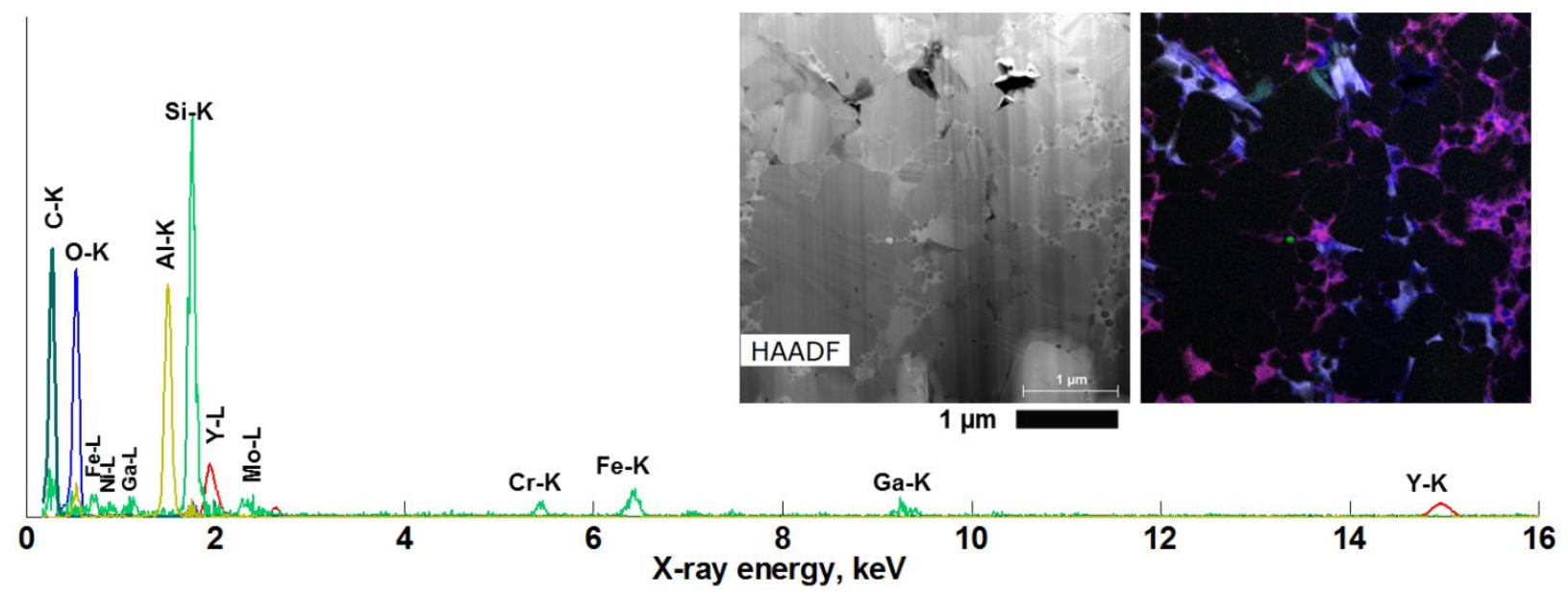

Figure 7: Color overlay composite of the score images and loading spectra of the data in Figure 4.

This $\mathrm{Al} / \mathrm{Y}$ separation is more clear at higher resolution. There are $\mathrm{Y}-\mathrm{Al}-\mathrm{O}$ and separate $\mathrm{Al}-\mathrm{O}$ (Figure 8). The inset shows the HAADF image, in which the oxides phases are white, the SiC matrix medium gray, and porosity dark. It also shows a false-color overlay of the combined score images arising from MVSA. The yellow feature at the top is the isolated Al-O phase; the light blue color at the lower triple-point and along the grain boundaries is a combination of the Al-O component (yellow) and Y-O component (blue). A cyan component, primarily Ga, surrounds the porosity and is a FIB sample preparation artifact. The red background is the $\mathrm{SiC}$ matrix.

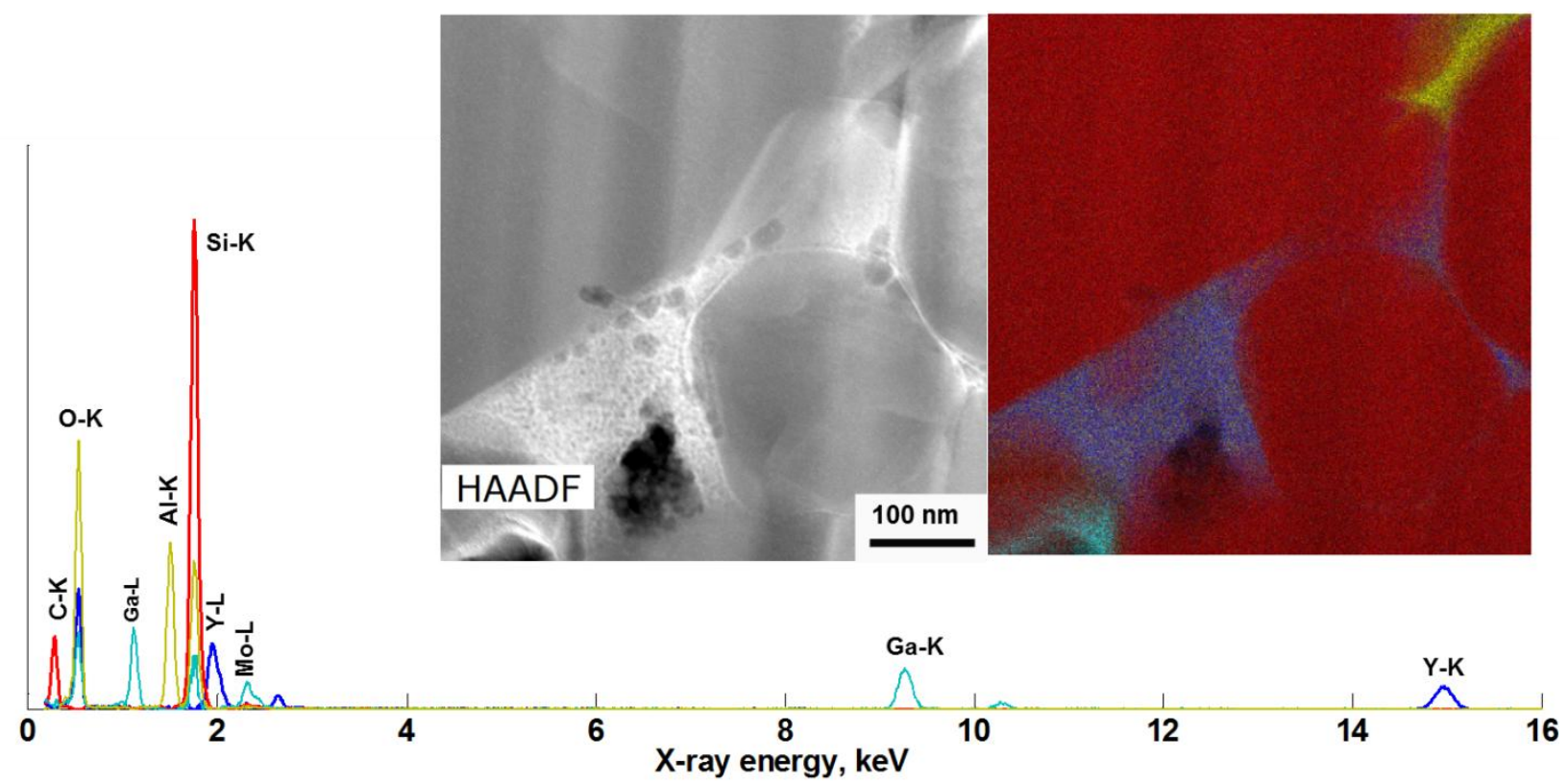

Figure 8: $H A A D F$, color-overlay score image, and loading spectra for a higher-magnification map of the uncorroded YA-NITE sample. 
Broadly speaking, the uncorroded YA-NITE material consists of both large $\sim 1 \mu \mathrm{m}$ grains and small $\mathrm{SiC}$ grains embedded in oxides at triple-points of the larger grains. The grain boundaries are wet by thin Y-Al-O phase, and triple-points are wet by either the $\mathrm{Y}-\mathrm{Al}-\mathrm{O}$ phase or a pure $\mathrm{Al}-\mathrm{O}$ phase.

The corroded YA-NITE is grossly different from the uncorroded. As noted by recession rates in Figure 2 , this sample suffered the highest corrosion attack after the PWR water chemistry immersion tests. The grain boundary oxide films and large triple-point packets have been entirely removed, and elongated blocky high-atomic-number (bright in HAADF) features have replaced the films and triple-point packets, Figure 9. The SiC matrix appears generally unchanged.

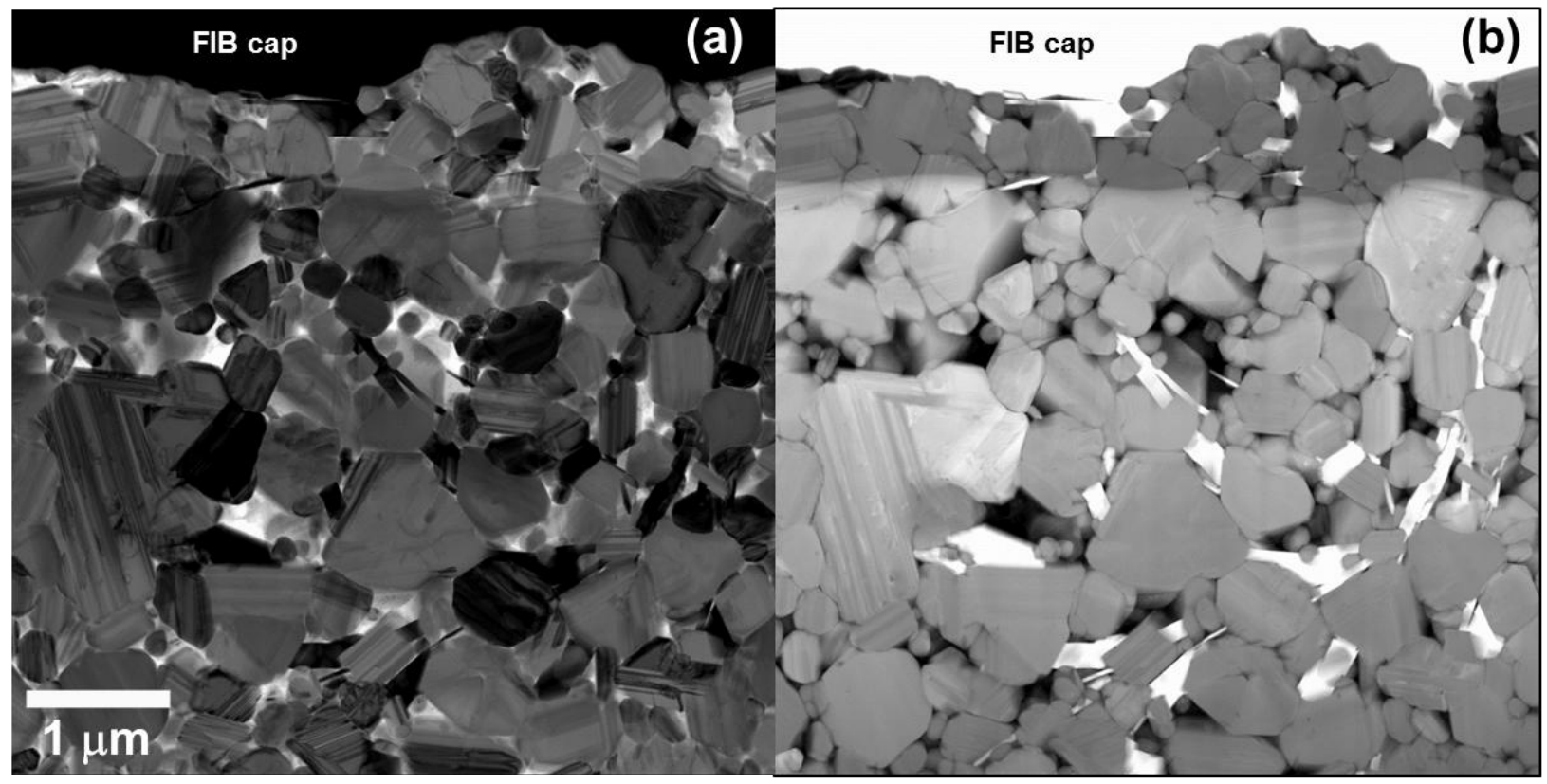

Figure 9: (a) bright field and (b) high-angle annular dark field images of the corroded YA-NITE specimen region. The band along the top is Pt deposited during FIB sample preparation.

The corrosion testing completely removed the $\mathrm{Al}$, and the large blocky features are essentially pure Y-O in Figure 10 (Al map). An MVSA reduction of the SI is summarized in Figure 11. Two sample-preparation artifact components, one of sparse Ga-implantation from FIB along the pores and thickness-step, and one showing FIB-induced Pt from the cap, are not shown. The Si-C matrix component is as expected, Figure 11a-11b. The Y-O component describes the blocky precipitates that have replaced the grain boundary films and triple-point packets in the uncorroded region, Figure 11c-11d. Two components describe another metallic inclusion, Figure 11e-11f. None of these loading spectra show Al counts above the noise level. Although there are apparent Al counts in the X-ray map of Figure 10, note that the full scale is $8 \mathrm{Al}-\mathrm{K}$ counts, compared to 25 for Figure 5; the $\mathrm{Al}$ counts in Figure 10 are all background, not characteristic. 


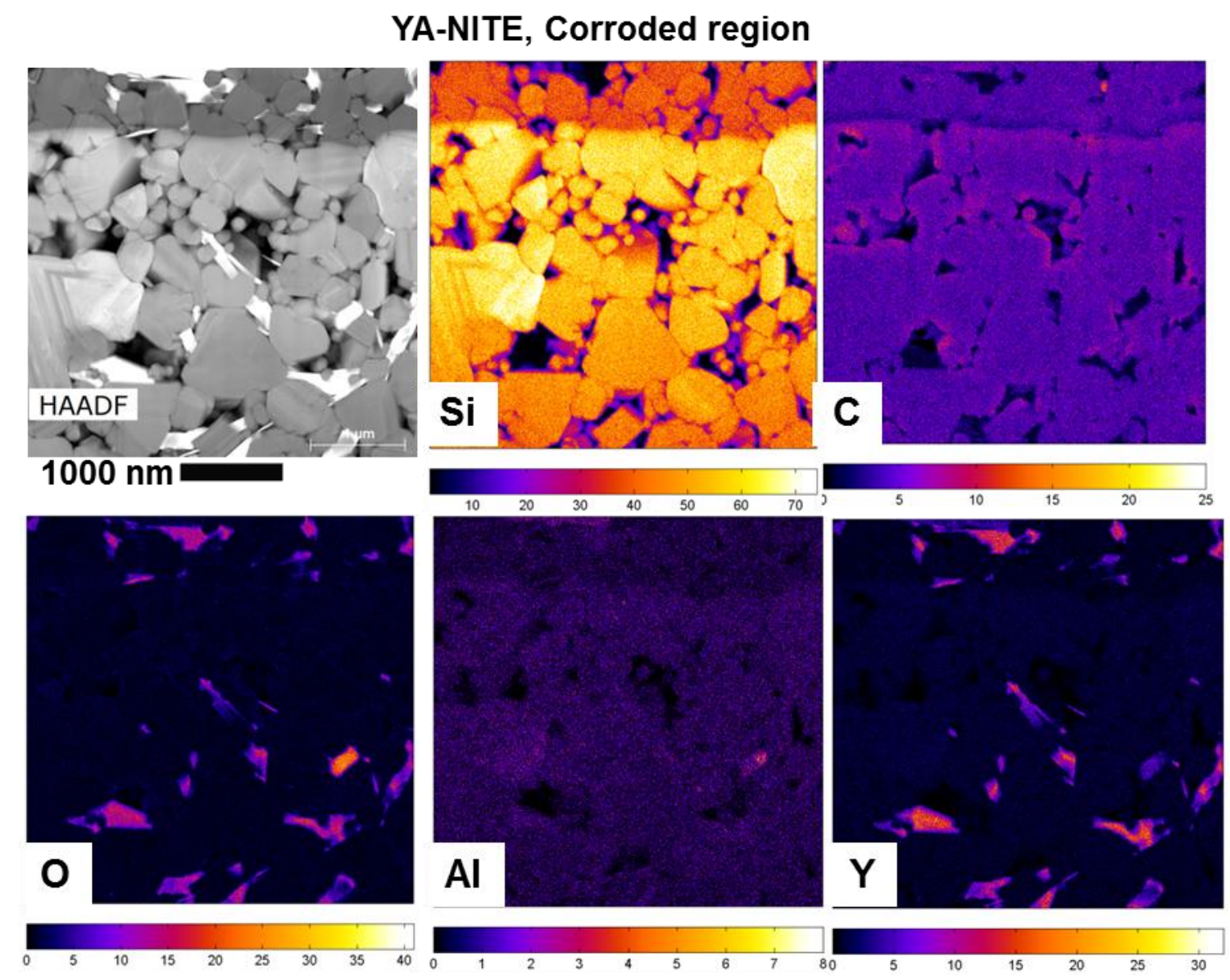

Figure 10: Low-magnification X-ray maps of the uncorroded YA-NITE region. Color bars are raw counts in the named $X$-ray line; all lines are the integrated $K$ series, except for $Y$, which is Ko. Change in signal near the top is a thickness variation.

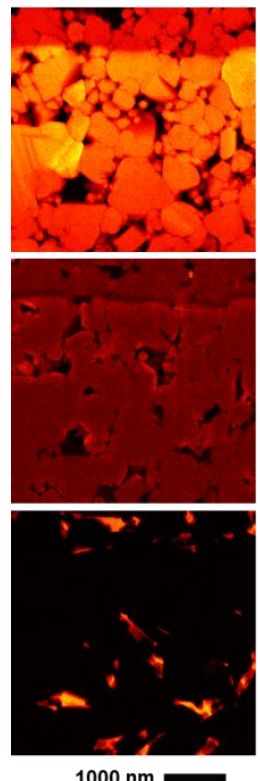

$1000 \mathrm{~nm}$
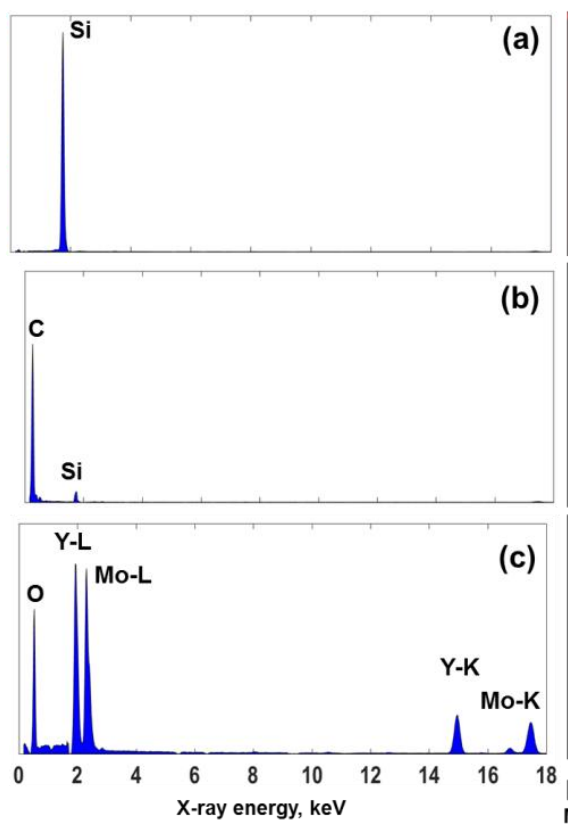

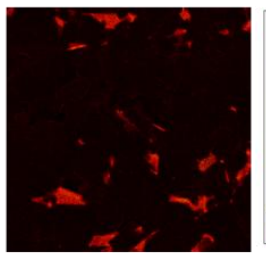

0

(d)

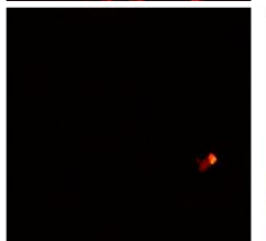

Y-L

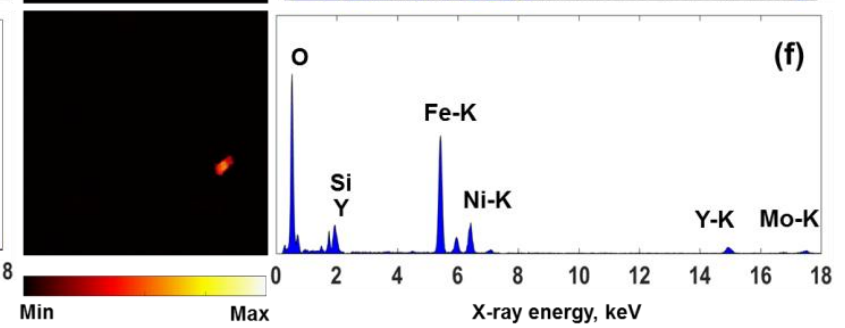


Figure 11: Score images and loading spectra from the MVSA analysis of the corroded YA-NITE specimen.

When examined at higher magnification, the blocky Y-O phases are more easily visible, and an Fe-Cr-Ni-O component is found at the grain boundaries, where the Y-Al-O phase had previously been, Figure 10. This Fe-Cr-Ni-O contribution, in place due to deposition of $\mathrm{Fe}, \mathrm{Cr}$, and $\mathrm{Ni}$ dissolved from the austenitic stainless steel autoclave vessel, was not readily expected, but MVSA presented it to us, again illustrating the "needle in a haystack" capability of the MVSA technique. In Figure 12, the HAADF image is seen, showing the SiC matrix (medium), open space (dark) and Y-O regions (bright). Empty space can be seen at the grain boundaries, where the corrosion has removed the oxide film. The color overlay in Figure 12 shows the SiC matrix (red), the Y-O blocks or needles (cyan) and the Fe-Cr-Ni-O phase (blue). The right image in Figure 12 is an intensity map of the Fe$\mathrm{Cr}-\mathrm{Ni}-\mathrm{O}$ phase alone, indicating that most of the surfaces or interfaces in the scanned region have been covered in Fe-Cr-Ni-O. An additional MVSA component of scattered Ga contamination from FIB preparation is not shown.

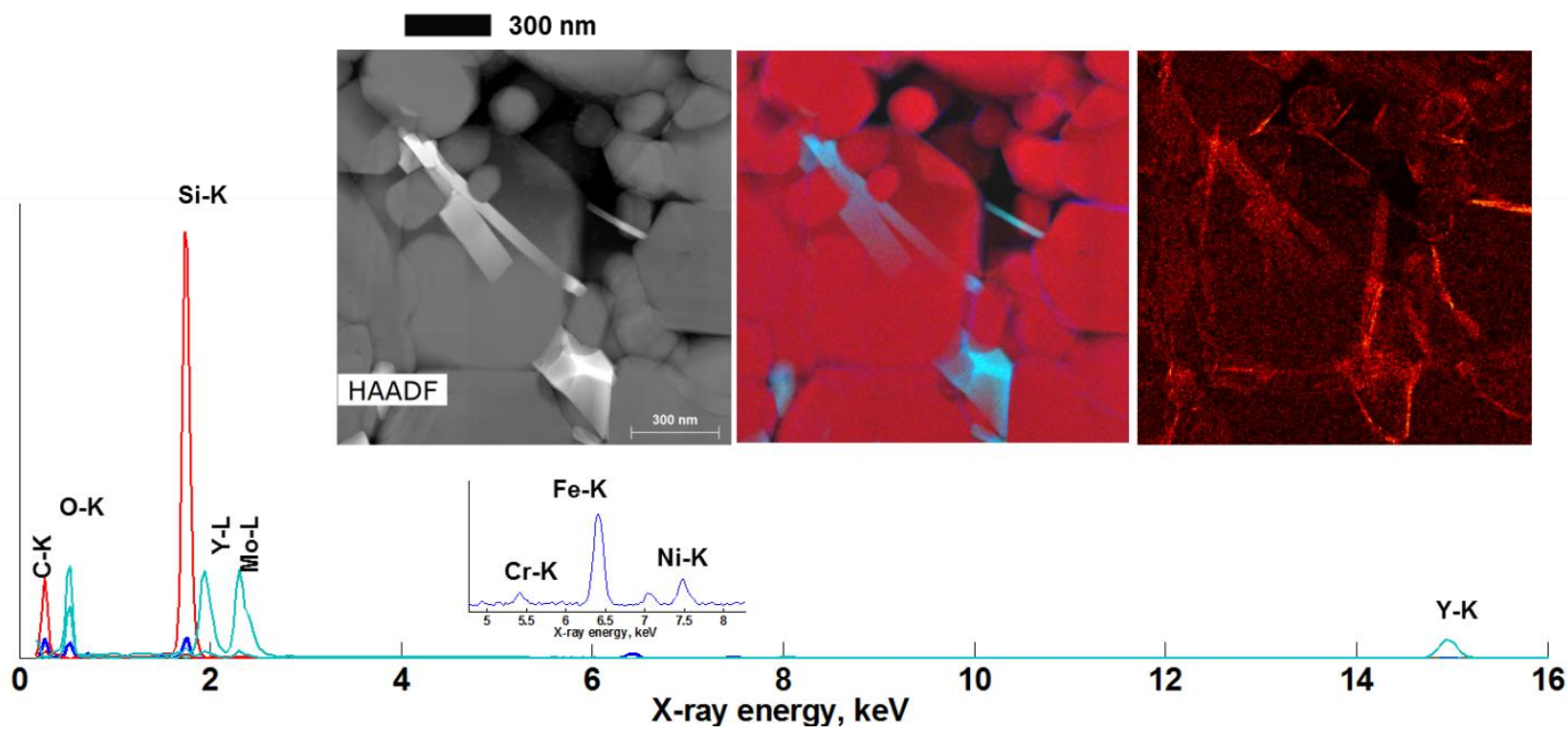

Figure 12: (bottom) loading spectra for three MVSA components. (top, left to right) HAADF image, false-color overlay of the score images (red: SiC, cyan: $\mathrm{Y}-\mathrm{O}$; blue: $\mathrm{Fe}-\mathrm{Cr}-\mathrm{Ni}$-O), and intensity image of the $\mathrm{Fe}$-Cr-Ni-O score image alone.

To summarize, the YA-NITE sample suffered the worst corrosion at the macroscopic scale after PWR immersion tests. Analysis using STEM indicated that the uncorroded structure consisted of large $(\sim 1000 \mathrm{~nm})$ and small $(<100 \mathrm{~nm}) \mathrm{SiC}$ grains, along with a population of Y-Al-oxides grain boundary films and triple-point packets, and Al-oxide grain boundary packets. The corrosion utterly removed the $\mathrm{Al}$, stripped most of the grain boundaries of their oxide films, and caused the Yoxides to change their morphology, typically into block or needle shapes. A thin layer of Fe-Cr-Ni-O appeared at the stripped grain boundaries and other interfaces.

\subsubsection{CZA-2-NITE: SiC-zirconia-ceria-alumina}

The CZA-2-NITE's uncorroded structure consists of large $(\sim 1 \mu \mathrm{m})$ highly faulted SiC grains with high-atomic-number oxides present as grain boundary films and triple-point pockets, Figure 
13. X-ray mapping indicates that the grain boundaries and some of the triple-point packets are mixed Ce-Al-O, with other triple-point packets being essentially pure $\mathrm{Zr}-\mathrm{O}$, Figure 14 . The overall $\mathrm{Al}$ counts are very small, as expected from the bulk composition (Table I).

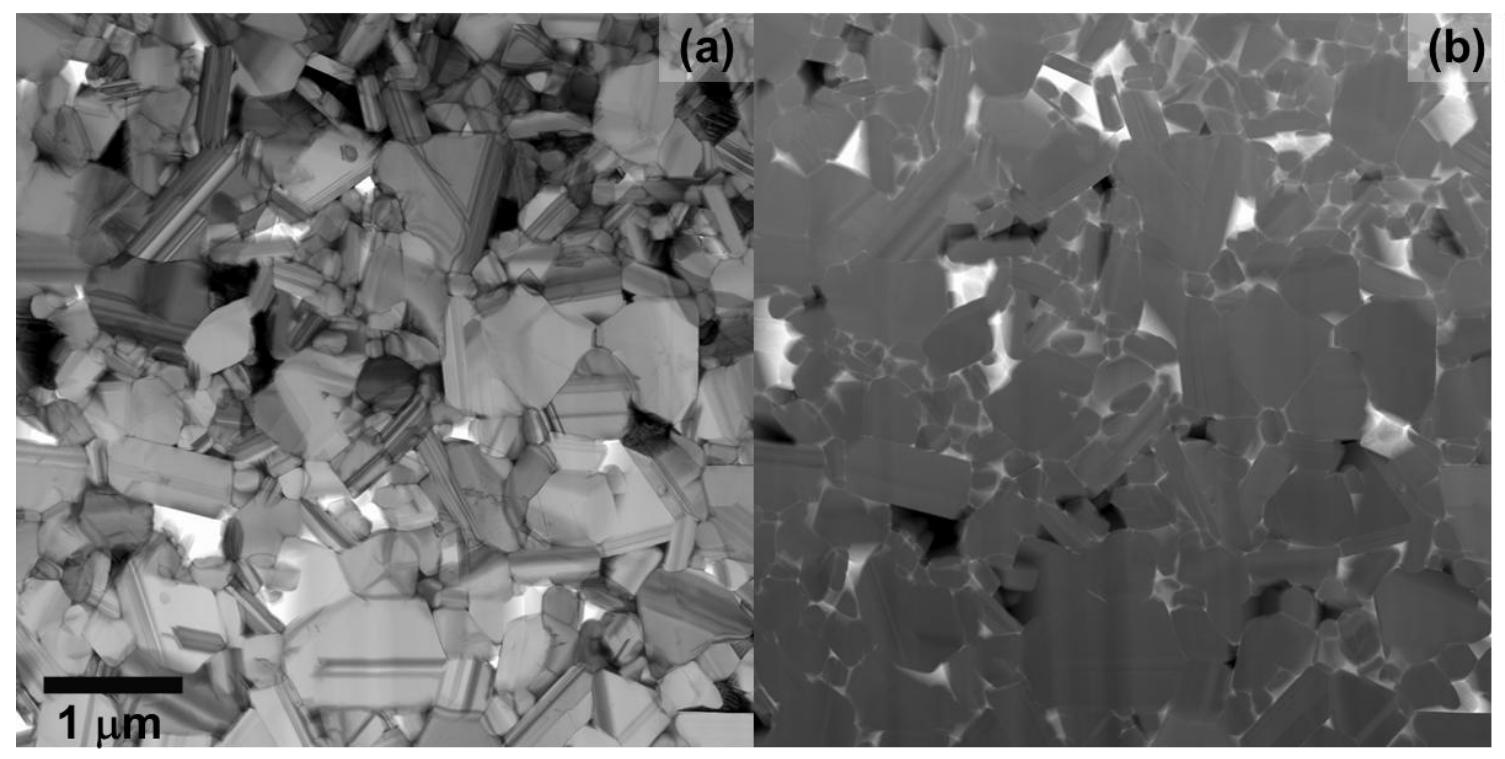

Figure 13: (a) BF and (b) HAADF images of the uncorroded CZA-2-NITE sample.

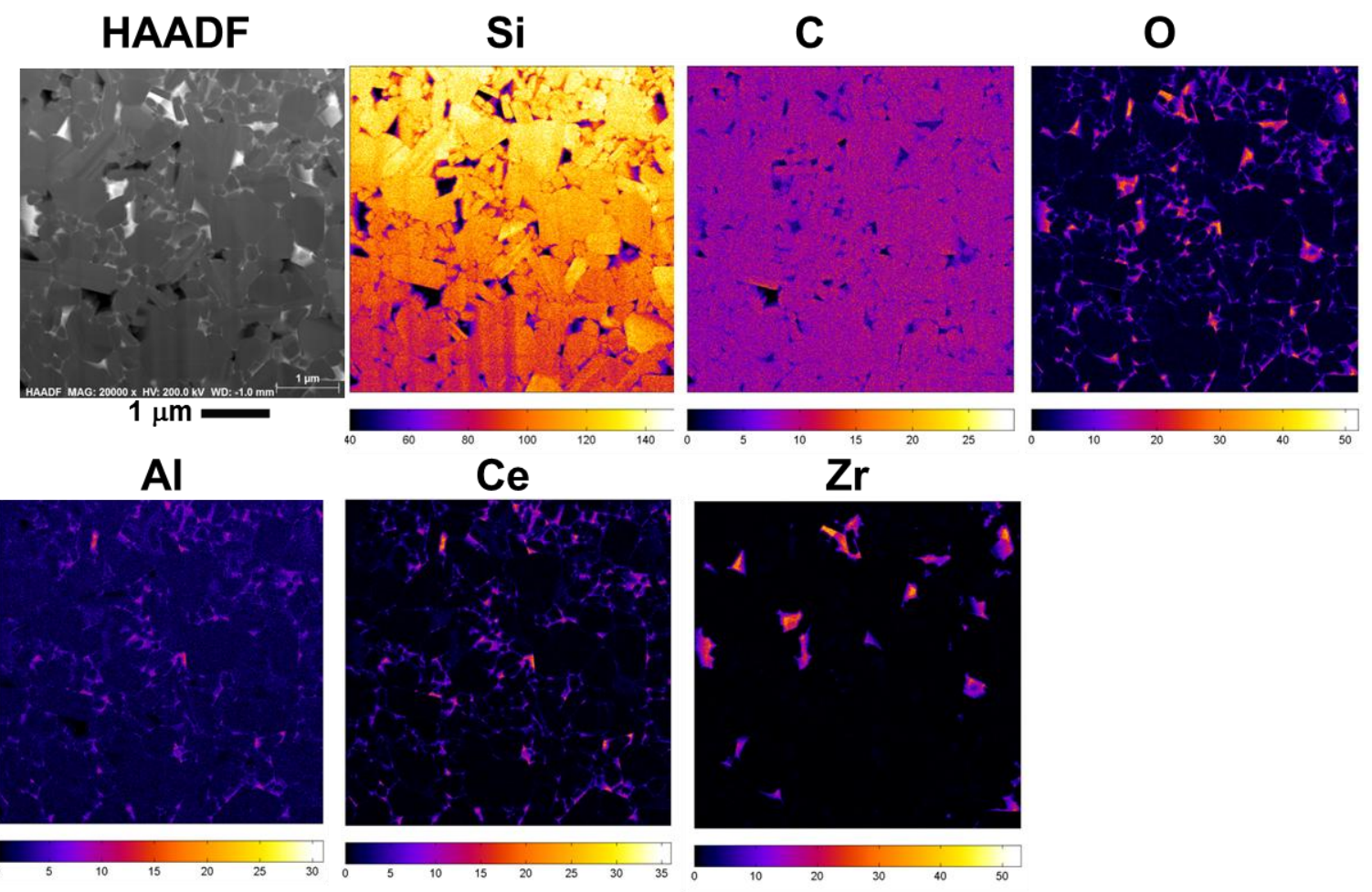

Figure 14: Low-magnification X-ray maps of the uncorroded CZA-2-NITE region. Color bars are raw counts in the named X-ray line; all lines are the integrated $K$ series, except for $\mathrm{Zr}$, which is $\mathrm{K \alpha}$, and Ce, which is $L \alpha$. 
The separation of $\mathrm{Zr}-\mathrm{O}$ and $\mathrm{Ce}-\mathrm{Al}-\mathrm{O}$ into two separate regions are confirmed by MVSA of the $\mathrm{X}$-ray SI, Figure 15. Two components, with different $\mathrm{Si} / \mathrm{C}$ ratios, describe the $\mathrm{SiC}$ matrix, as expected (Figure 13a-13b). Zr-O (Figure 13c), O (Figure 13d) and Ce-Al-O (Figure 13e) components are also found separately. Even though the pixel pitch in this low magnification is rather large $(\sim 5 \mathrm{~nm})$, the grain boundary films are still quite visible in the 0 (Figure 13d) and Ce-Al-O (Figure 13e) maps, indicating the grain boundaries are mostly coated in a Ce-Al-oxide. The $\mathrm{Zr}-\mathrm{O}$ is mostly confined to the large triple-point packets. Because the specimen area is wedge-shaped, a second $\mathrm{Zr}$ component (containing the high-energy $\mathrm{Zr}$ lines) is seen in the thick region, Figure $13 \mathrm{f}$.

A color overlay of the $\mathrm{Zr}-\mathrm{O}$, Ce-Al-O, and $\mathrm{O}$ components (Figure 16) illustrates the separation of the $\mathrm{Zr}-\mathrm{O}$ and $\mathrm{Ce}-\mathrm{Al}-\mathrm{O}$ into separate regions, rather than a well-mixed eutectic of the three cations. This implies that ceria does not dissolve as much in the cubic zirconia matrix and instead spreads along with aluminum at the grain boundaries. The dissolution-resistant zirconia instead is segregated in islands and fails to protect the $\mathrm{SiC}$ grains.
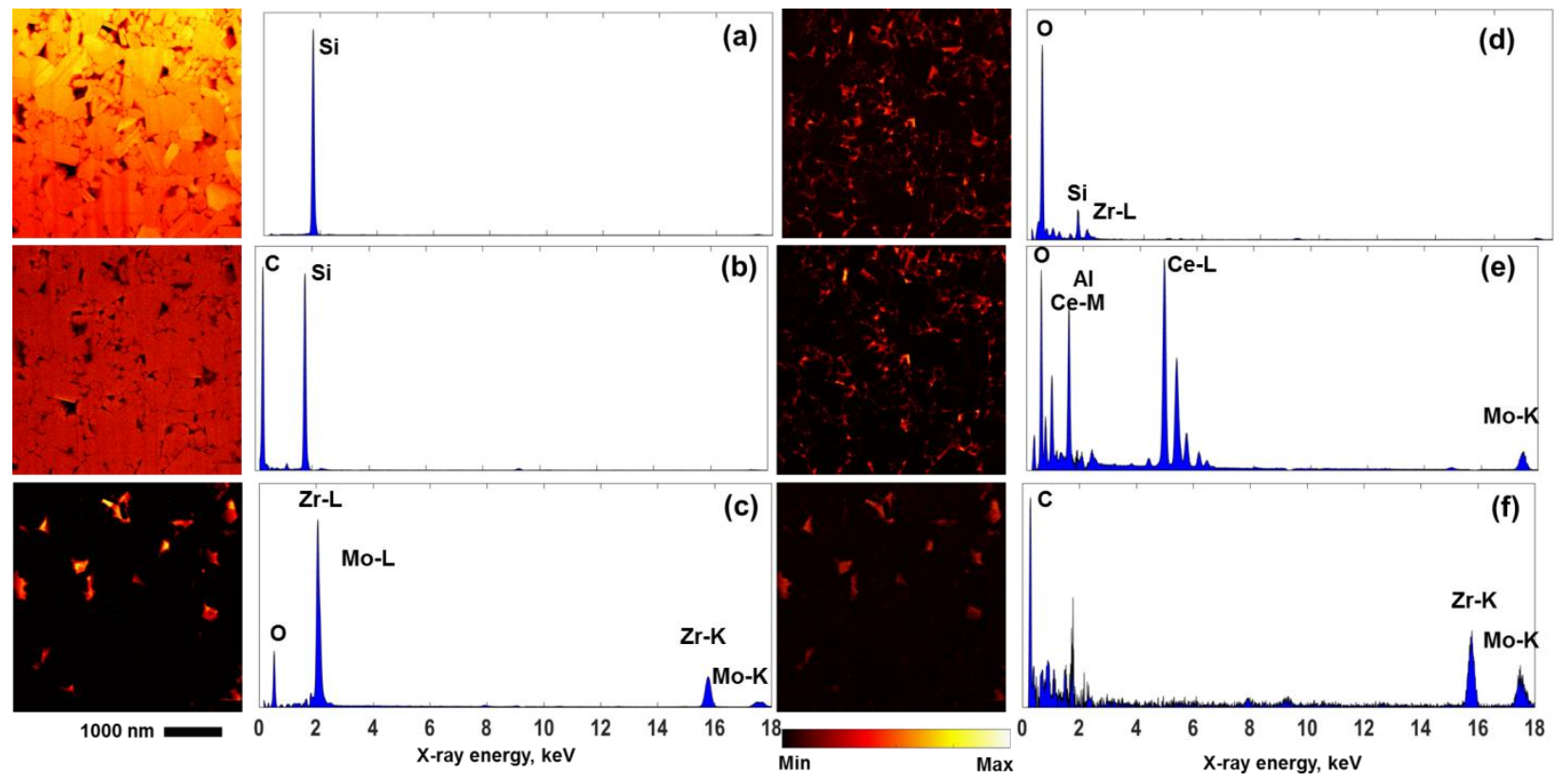

Figure 15: Score images and loading spectra from the MVSA analysis of the uncorroded CZA-2-NITE specimen. 


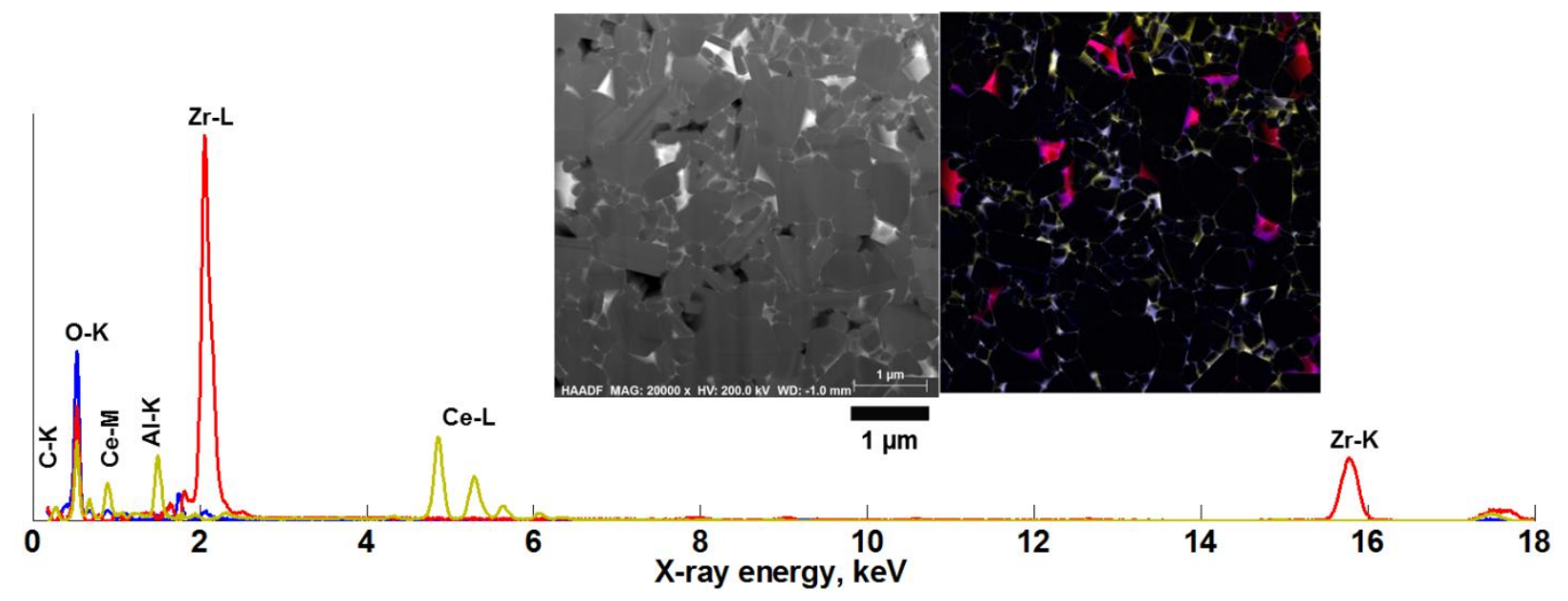

Figure 16: CZA-2-NITE, uncorroded. HAADF image and color overlay of the Zr-O (red), Ce-Al-O (yellow), and $O$ (blue) component score images, along with associated loading spectra.

A more detailed view of the CZA-NITE uncorroded structure confirms the above description. A higher-resolution X-ray map, followed by MVSA, indicates that, indeed, the grain boundaries are outlined in Ce-Al-O and triple-point packets are either Ce-Al-O or Zr-O, Figure 17. Additionally, the MVSA color overlay in Figure 15 shows some blue ( 0 -component) features (arrowed), without the cations (Ce, $\mathrm{Al}, \mathrm{Zr}$ ) components being present. Inspection of the HAADF image indicates these are pores in the structure, so we infer very thin silica layers on the pore surfaces.

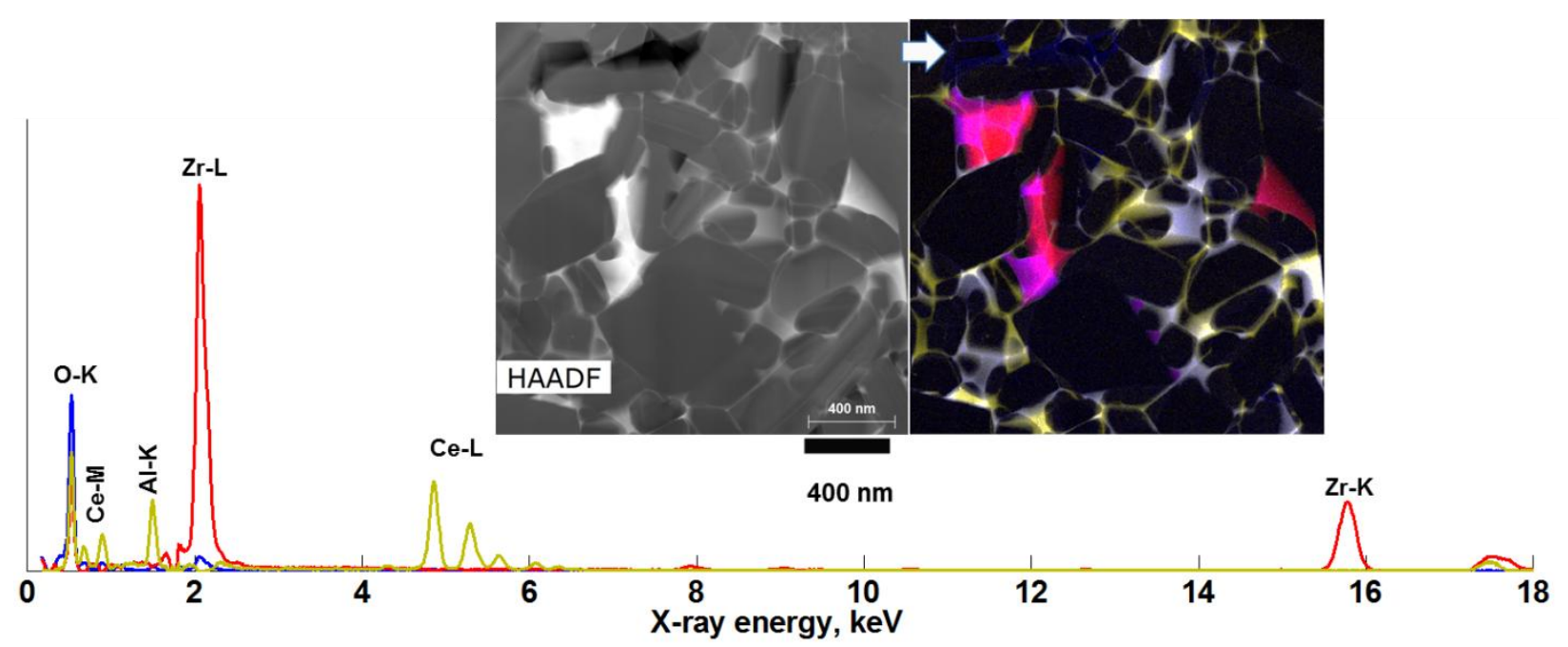

Figure 17: Higher magnification map of the uncorroded CZA-2-NITE. HAADF image and color overlay of the Zr-O (red), Ce-Al-O (yellow), and O (blue) component score images, along with associated loading spectra. 
The corroded CZA-2-NITE structure resembles the corroded YA-NITE structure, in that the $\mathrm{Al}$ cation has been removed, empty space appears at the boundaries, and an Fe-O film appears on many of the free surfaces in the structure. The general microstructure is given in Figure 18 and lowmagnification X-ray maps in Figure 19. Importantly, no Al counts above the background are seen in the X-ray maps, and significantly less Ce is seen along the grain boundaries.

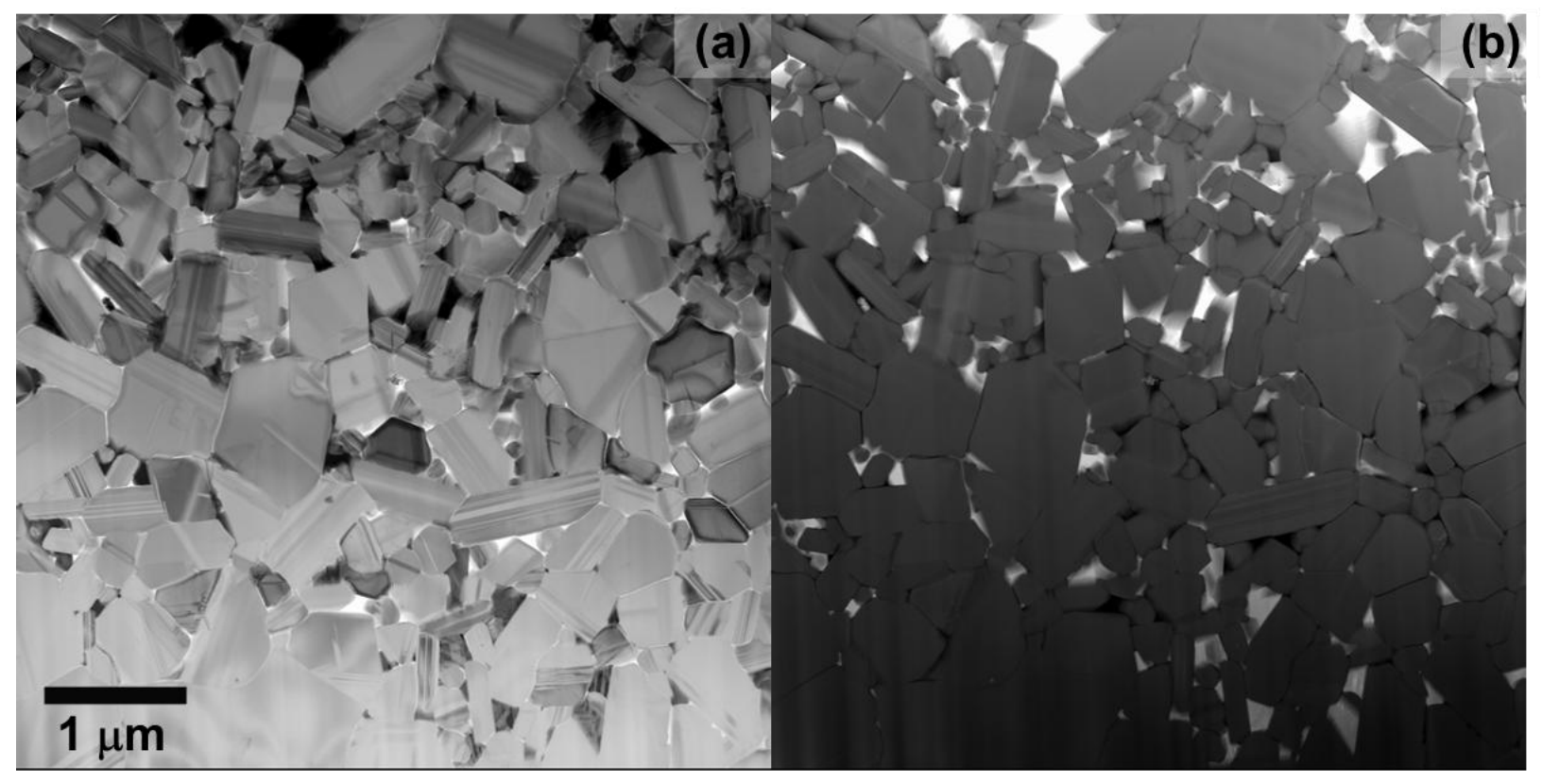

Figure 18: (a) BF and (b) HAADF images of the corroded CZA-2-NITE sample. 

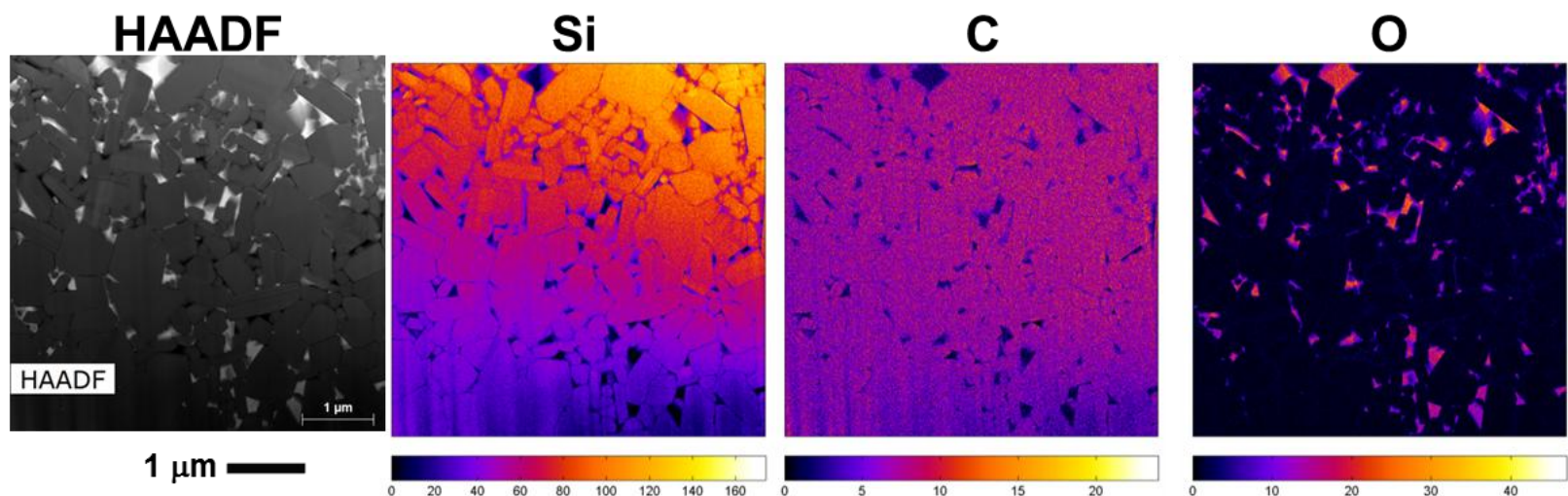

Al

$\mathrm{Ce}$
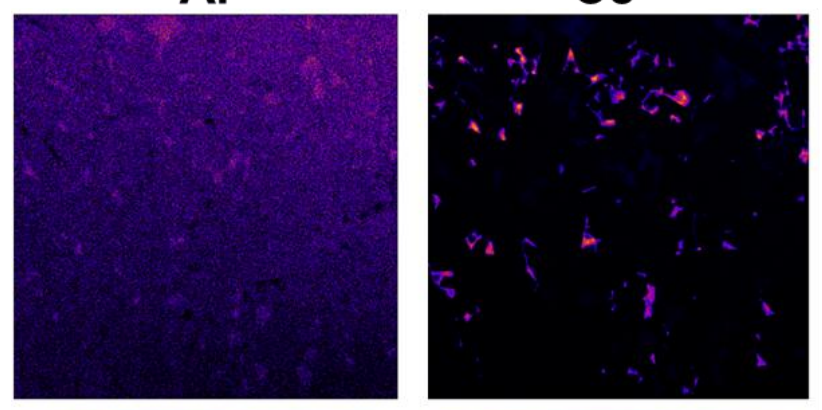

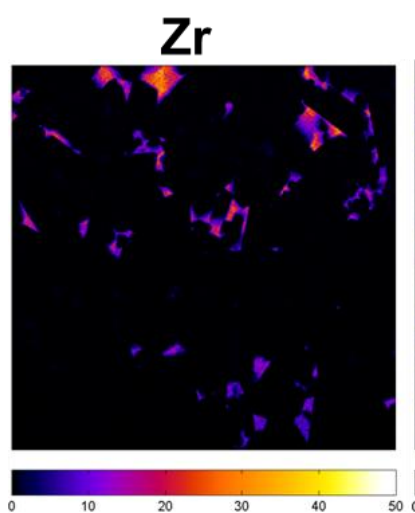

$\mathrm{Fe}$

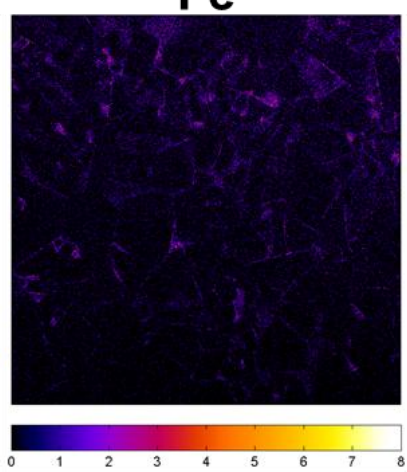

Figure 19: Low-magnification X-ray maps of the uncorroded CZA-2-NITE region. Color bars are raw

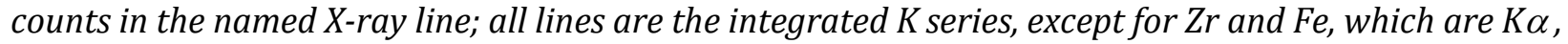
and Ce, which is L $\alpha$. (The region is thinner at the bottom than at the top, as seen in the HAADF gradient and Si count gradient.)

MVSA reveals the separated $\mathrm{Ce}-\mathrm{O}$ and $\mathrm{Zr}-\mathrm{O}$, shows a clear Fe-O grain boundary and free surface component, and shows the $\mathrm{SiC}$ matrix, Figure 20. Because the mapped region has a wedge shape, the matrix is broken into a $\mathrm{Si}$ and a $\mathrm{SiC}$ component (Figure 20a-20b), due to the high absorption of $C$ in the matrix. The next two components shows $\mathrm{Zr}$ (Figure 20c), Fe-O (Figure 20d), and $\mathrm{Zr}-\mathrm{L}$ and $\mathrm{O}-\mathrm{K}$ lines (Figure 20e), again due to changes in absorption across the wedge. Lastly, Ce-O (Figure 20f) component was discovered by MVSA. No Al counts are seen in any MVSA component. 


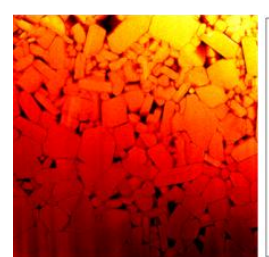

(a)
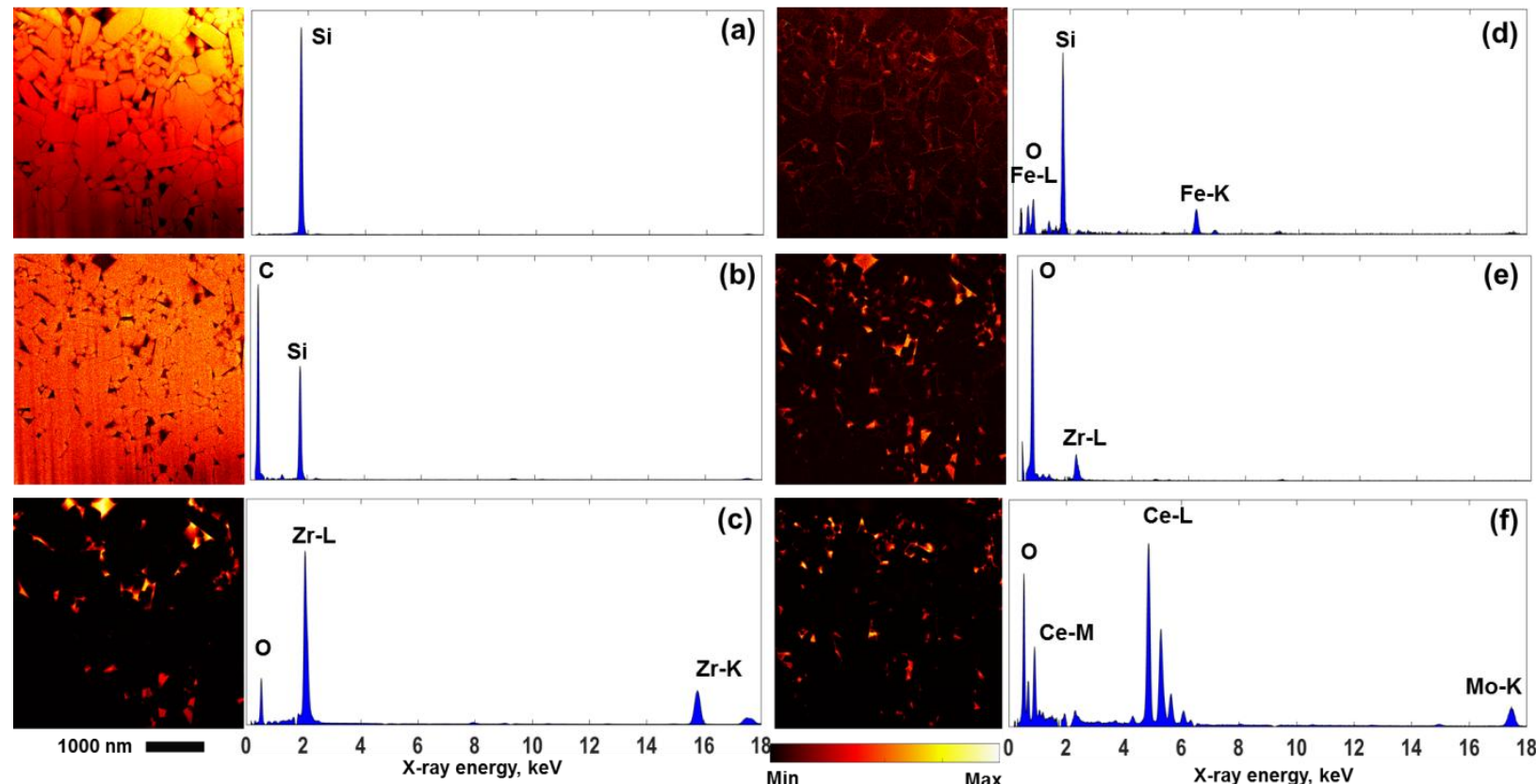

c)

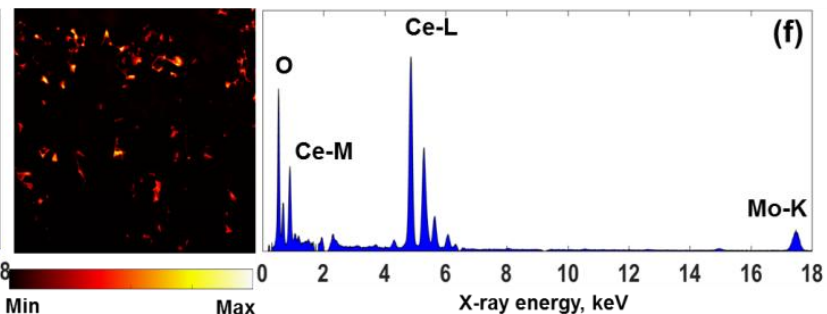

Figure 18: Score images and loading spectra from the MVSA analysis of the corroded CZA-NITE specimen.

High-magnification mapping (Figure 21) confirms these interpretations: Zr-O triple-point packets remain essentially unchanged; Al disappears; a small amount of Ce-O remains at a few grain boundaries and at some of the triple-points; and Fe-O films line most of the prior grain boundary surfaces.

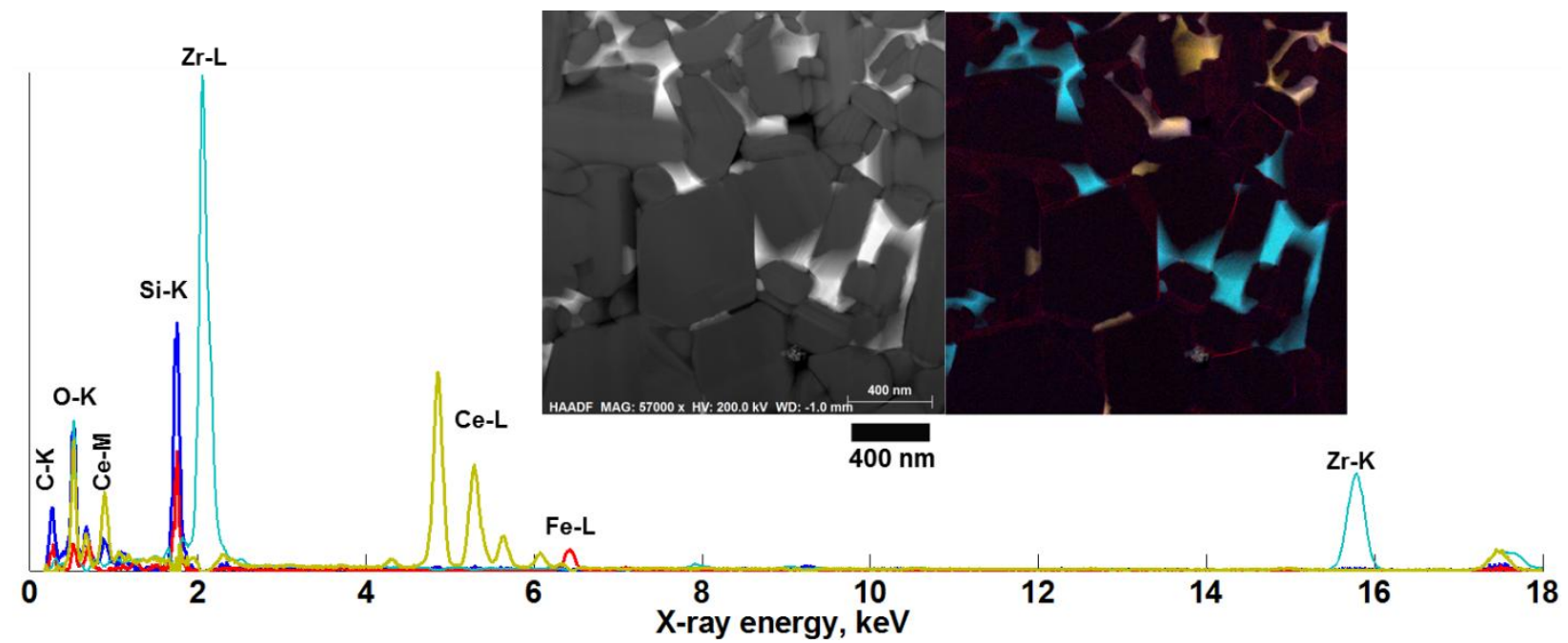

Figure 21: Higher magnification map of the corroded CZA-NITE. HAADF image and color overlay of the $\mathrm{Zr}-\mathrm{O}$ (cyan), $\mathrm{Ce}-\mathrm{O}$ (yellow), and $\mathrm{Fe}-\mathrm{O}$ (red) component score images, along with associated loading spectra. 
To summarize, the CZA-2-NITE sample suffered moderate corrosion at the macroscopic scale. Analysis using STEM indicated that the uncorroded structure consisted of large $(\sim 1000 \mathrm{~nm})$ $\mathrm{SiC}$ grains, along with a population of Ce-Al-oxides grain boundary films and triple-point packets, and $\mathrm{Zr}$-oxide grain boundary packets. The corrosion utterly removed the Al, stripping most of the grain boundaries of their oxide films. Ce-oxide and Zr-oxide remained in discrete packets, primarily at triple-points. A thin layer of $\mathrm{Fe}-\mathrm{O}$ appeared at the stripped grain boundaries and other interfaces.

\subsubsection{YZA-NITE: SiC-yttria-zirconia-alumina}

The uncorroded YZA-NITE material consisted of large $(\sim 1 \mu \mathrm{m}) \mathrm{SiC}$ grains, with Y-Al-oxides present as grain boundary films, and with Y-Zr-oxides present as fairly large triple-point packets, Figures 22-23. Because of the strong background count generation in the Y-Zr-oxide, the Al counts that appear to be present in the triple-point packets are not necessarily real, and are analyzed in more detail below.

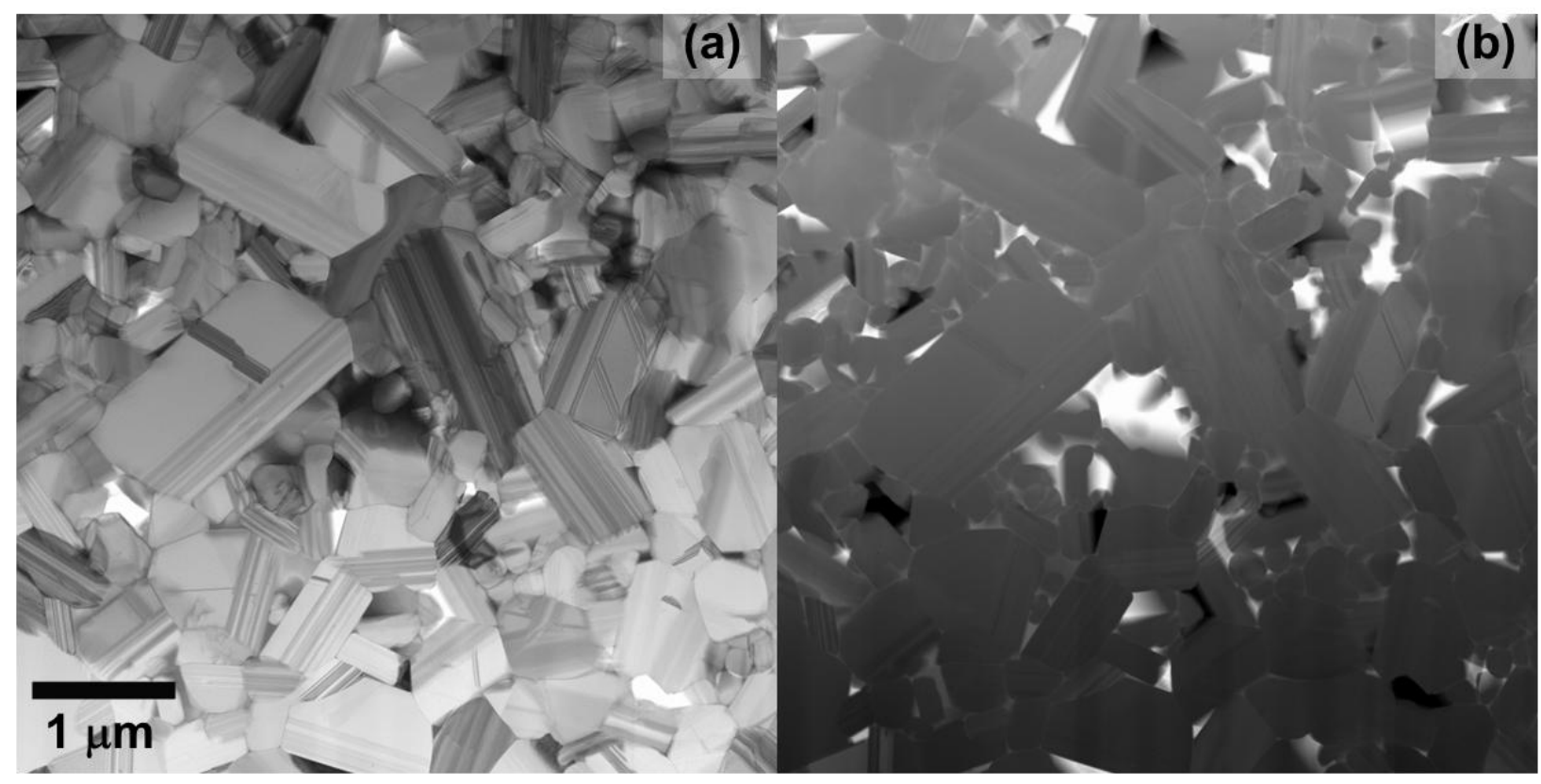

Figure 22: (a) BF and (b) HAADF images of the uncorroded YZA-NITE sample. 

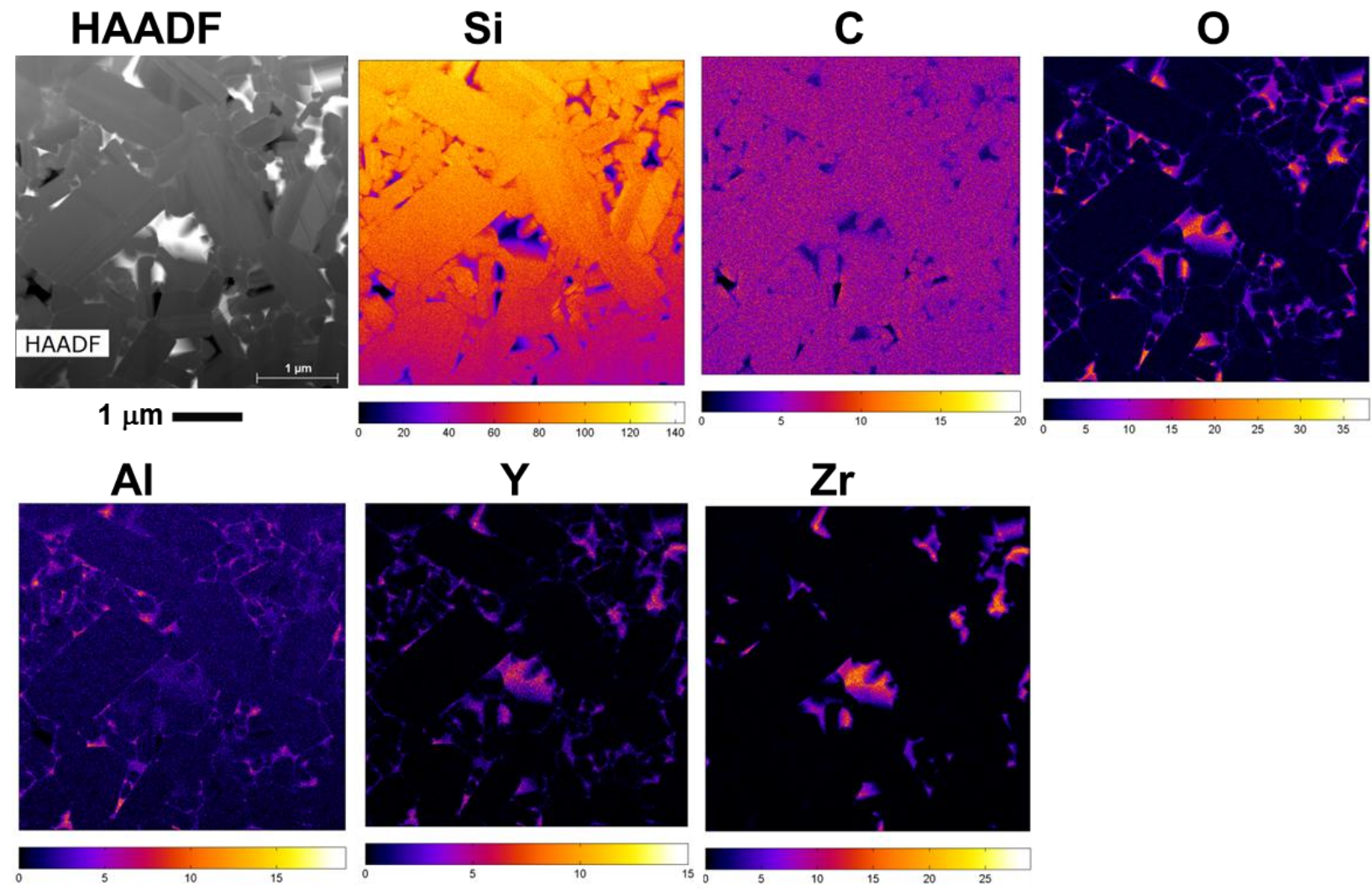

Figure 23: Low-magnification X-ray maps of the uncorroded YZA-NITE region. Color bars are raw counts in the named $X$-ray line; all lines are the integrated $K$ series, except for $Z r$ and $Y$, which are $K \alpha$.

MVSA reduction (Figure 24) of the SI data finds the correlations between the three cations, confirming the univariate analysis (Figure 23) that the grain boundaries are primarily Y-Al-oxide and the triple-points Y-Zr-oxide. The first two components (Figure 24a-24b) show the SiC matrix. The third component (Figure 24c) shows the Zr and Y lines, with a weak $\mathrm{O}$ contribution. The fourth component (Figure 24d) shows Y-Zr L-lines and strong 0 , which is essentially the same as component \#3 (Figure 24c) but with differences arising due to absorption of the soft X-rays in the sample's finite thickness. The fifth component (Figure 24e) shows $\mathrm{Al}, \mathrm{Y}$, and $\mathrm{O}$, are present primarily as grain boundary films, but with a few smaller triple-point packets, and with some minor contributions to the larger Y-Zr-oxide packets. Thus, MVSA indicates a strong but not total separation between the Y-Al-oxide and Y-Zr-oxide phases, with the grain boundaries being mostly Y-Al-oxide. 

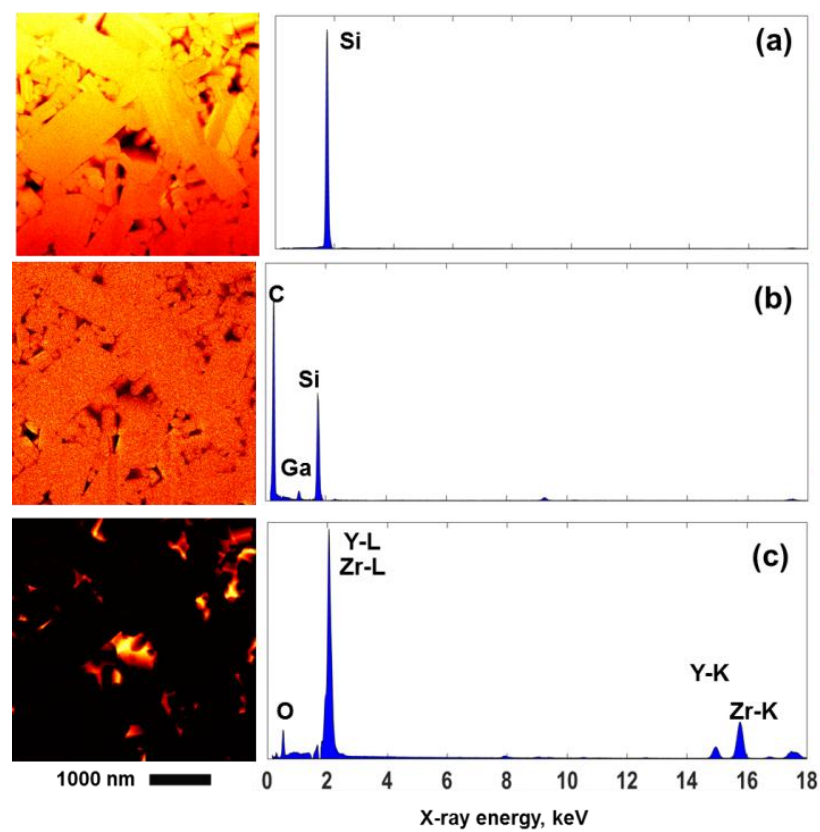

$1000 \mathrm{~nm}$

X-ray energy, keV (a)

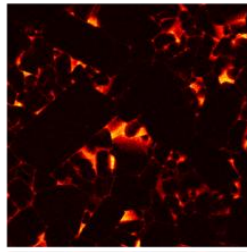

o

(d)

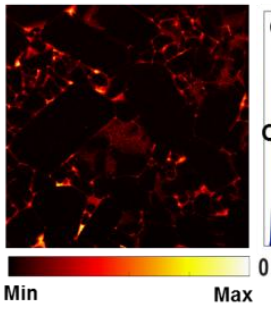

(e)

Figure 24: Score images and loading spectra from the MVSA analysis of the uncorroded YAA-NITE specimen.

Higher-magnification X-ray mapping indicates that the Y-Al-oxide layer may be coating the Y-Zr-oxide triple point packets, (apart from the morphology described above). MVSA reduction of a high-magnification map, Figure 25, shows the SiC matrix (Figure 25a), two Y-Al-oxide components (Figure 25b-25c), and the Y-Zr-oxide packets (Figure 25d). A false-color overlay (Figure 25f), along with comparison of the score images in Figure 25b-25d, shows that the Al-bearing region appears to form a thin shell around the Zr-rich packets. An HAADF image is also given in Figure 25e. At even higher magnification, Figure 26, the grain boundaries are shown to be Y-Al-oxide (Figure 26a-26b), and the Y-Al-oxide wrapping around a Y-Zr-oxide packet (Figure 26c). A HAADF image (Figure 26d) and false-color overlay (Figure 26e) are also shown.
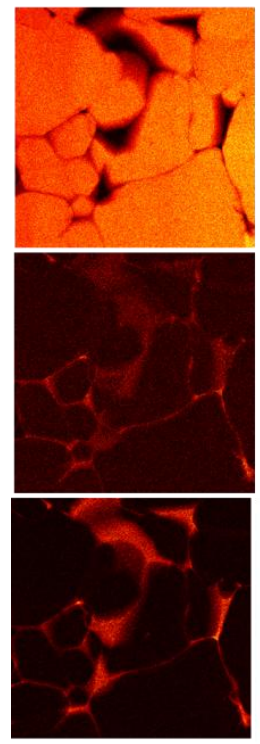

$300 \mathrm{~nm}$
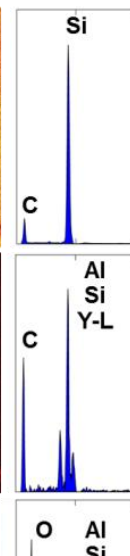

Y.L
Al
Si
$Y-L$

L

(a)
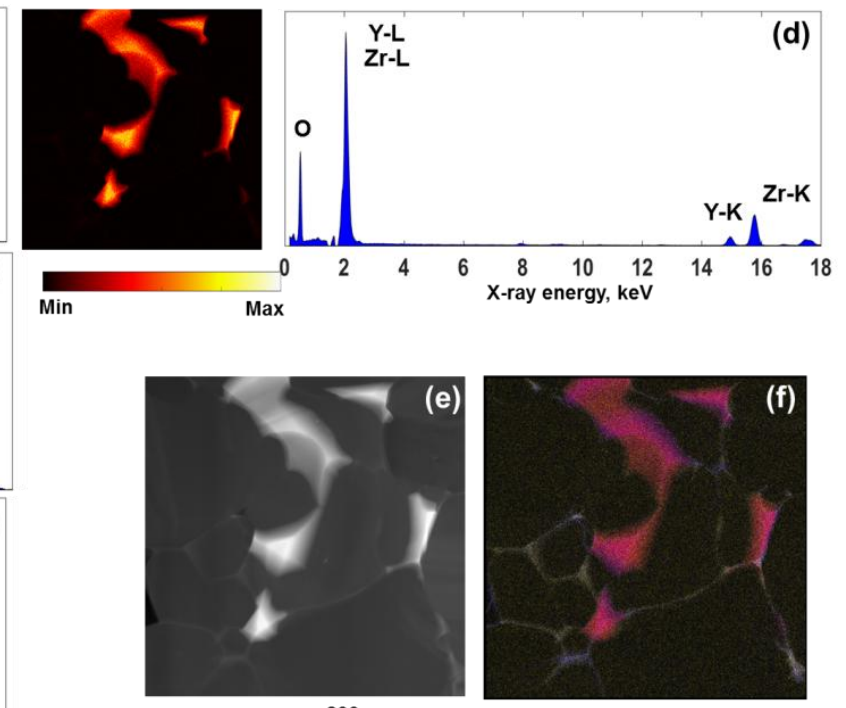

(c)

Y-K

$200 \mathrm{~nm}$ 
Figure 25: MVSA reduction of high-resolution data for the YZA-NITE uncorroded sample. (a)-(d): score image/loading spectra pairs. (e) HAADF image. (f) Color composite overlay.

At even higher magnification, these same results continue to appear (Figure 26). An MVSA reduction of a very fine-scale map shows matrix (Figure 24a), the thin grain-boudnary film of Y-Aloxide (Figure 24b) and a packet of Y-Zr-oxide (Figure 24c). The Y-Al-oxide is also seen to be weakly present at the location of the Y-Zr-oxide packet. In the false-color overlay (Figure 26e), the Y-Aloxide phase (yellow) is seen to surround the Y-Zr-oxide phase (blue) with a width of a few pixels (few nm). A HAADF image is also presented (Figure 26d).

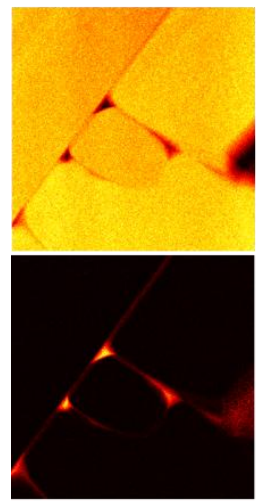

$100 \mathrm{~nm}$

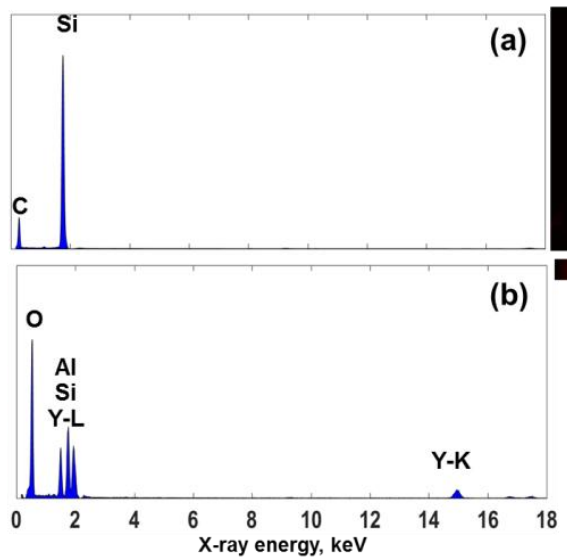

(a)
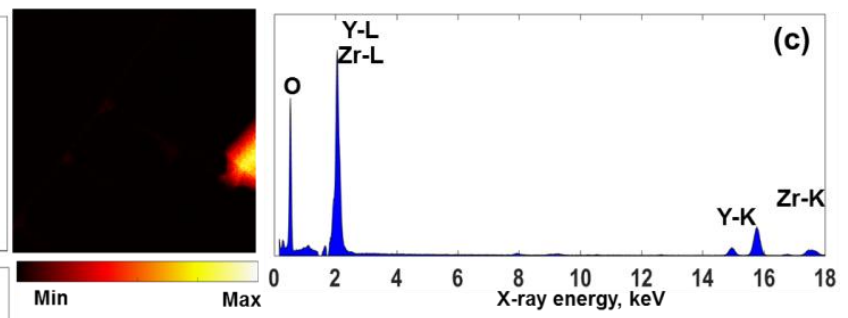

(d)

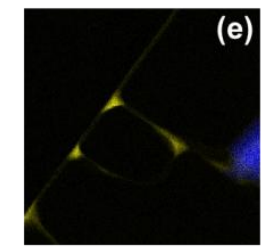

Figure 26: MVSA reduction of high-resolution data for the YZA-NITE uncorroded sample. (a)-(c): score image/loading spectra pairs. (d) HAADF image. (e) Color composite overlay.

In the corroded YZA-NITE, unlike the YA-NITE or CZA-2-NITE, a small amount of Al is still detectable after the hydrothermal corrosion. The gross microstructure (Figure 27) of the corroded region shows that the grain structure is essentially unchanged compared to the uncorroded state, but that many of the grain boundaries contain open space instead of high-atomic-number oxides (Figure 27b). X-ray mapping (Figure 28) shows the grain boundaries are partly stripped of the transient eutectic cations $(\mathrm{Y}, \mathrm{Zr}, \mathrm{Al})$ and a small amount of $\mathrm{Fe}$ has been deposited there. 


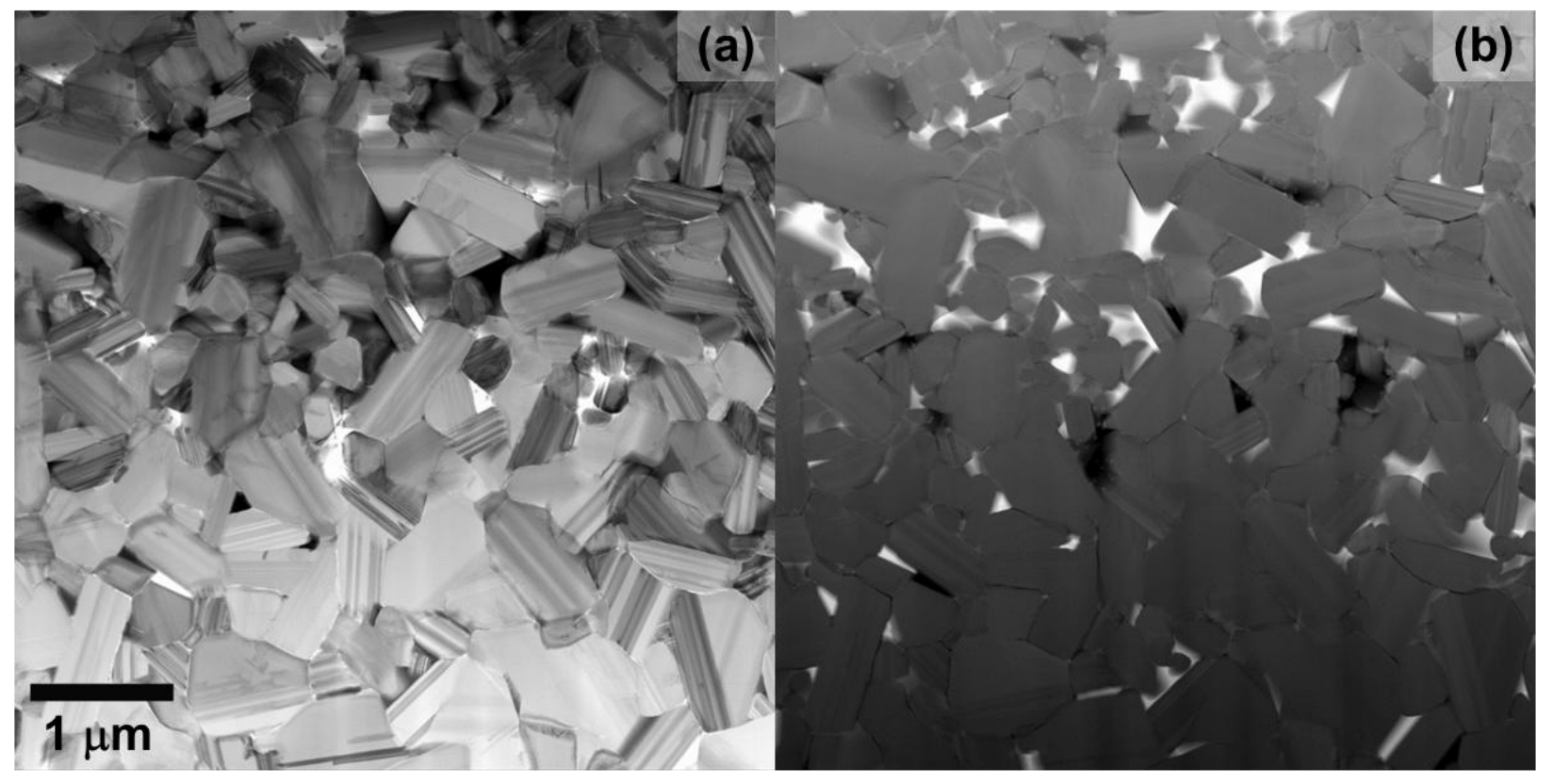

Figure 27: (a) BF and (b) HAADF images of the corroded YZA-NITE sample.

\section{HAADF}

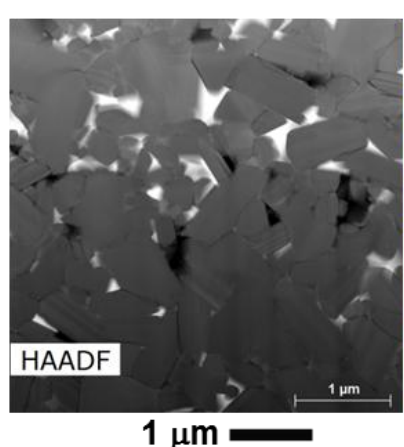

Al

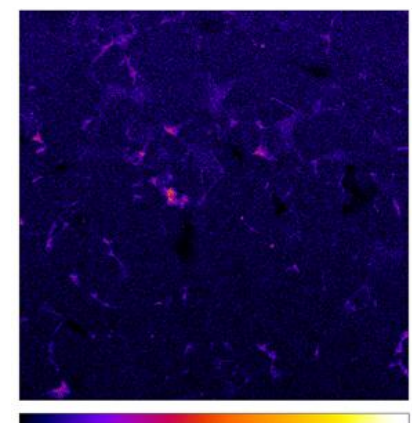

$\mathrm{Si}$

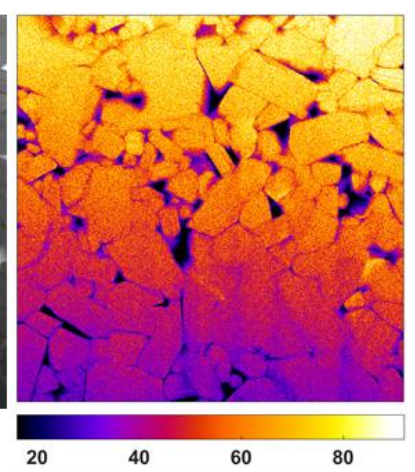

Y

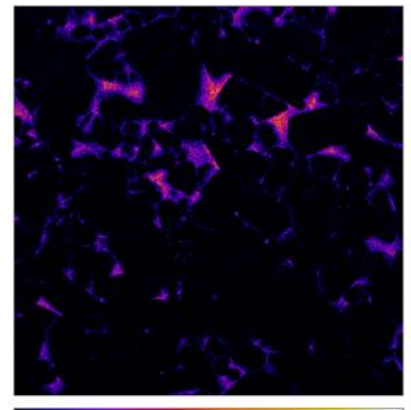

C

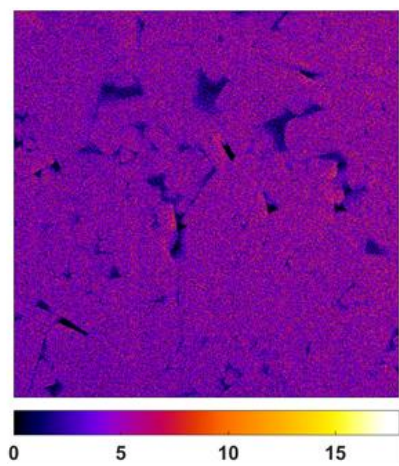

$\mathrm{Zr}$

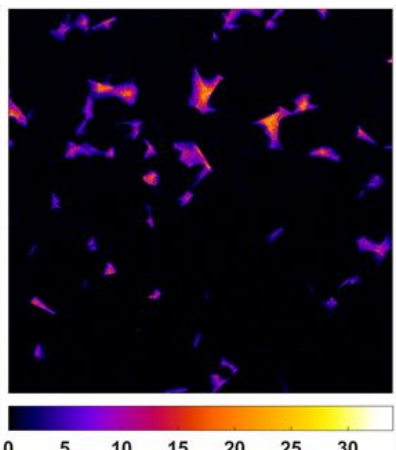

0

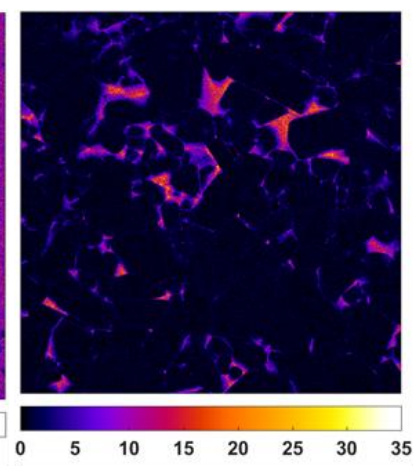

$\mathrm{Fe}$

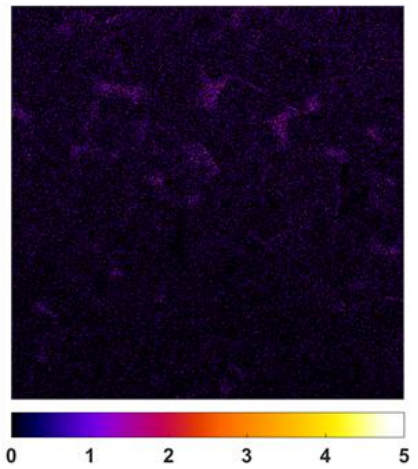

Figure 28: Low-magnification X-ray maps of the corroded YZA-NITE region. Color bars are raw counts in the named X-ray line; all lines are the integrated $K$ series, except for $Z r$, Fe, and $Y$, which are Ko. 
X-ray mapping has the major drawback that heavy elements (i.e., Zr, Y) produce extra background counts in bins such as that for Al; MVSA, by discovering the peak shapes of the underlying chemical contributions, eliminates this artifact and presents the "Al" information as a peak (or lack of a peak) rather than simple counts. MVSA reduction of this YZA-NITE corroded data unambiguously shows that some $\mathrm{Al}$ has survived the corrosion, unlike the YA- and CZA-NITE. The first two MVSA components, Figure 29a-29b, show the SiC matrix. The third component, Figure 29c, shows an Al-bearing Y-Al-oxide phase, present mostly at triple-point packets but with scattered contributions along the grain boundaries. The fourth, fifth, and sixth components (Figures 29d-29f) are a complex mix of Zr-Y-oxides, mostly at grain boundary packets, and with a small amount of Fe present as well.
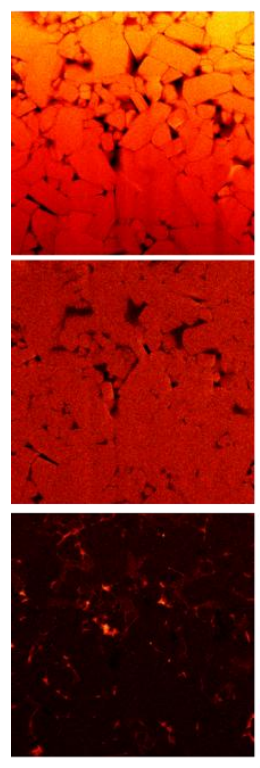

$1000 \mathrm{~nm}$

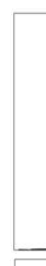

.
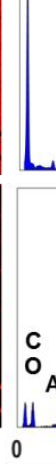
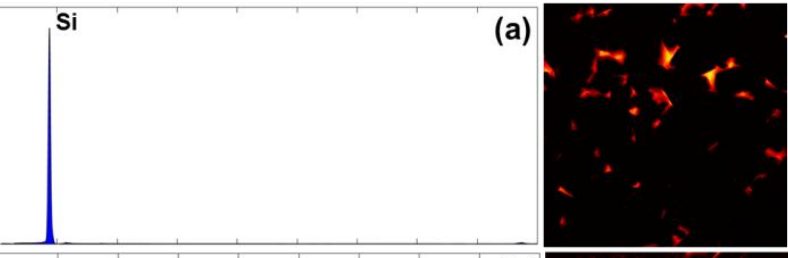

(b)

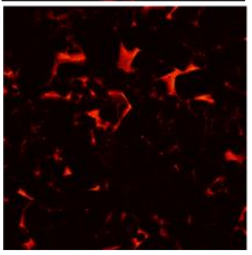

(c)

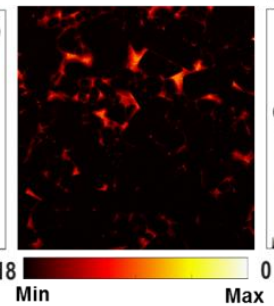

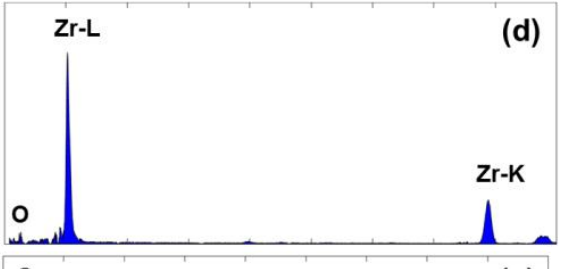

(e)

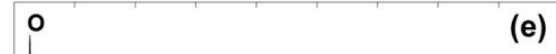

Yr-L

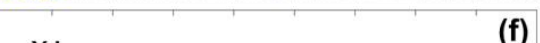

Y-L

0

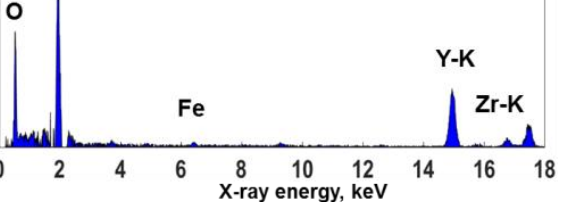

Figure 29: Score images and loading spectra from the MVSA analysis of the corroded YAA-NITE specimen.

At higher magnification, it is confirmed that the grain boundaries still contain the Y-Al-oxide phase (Figure 30, yellow MVSA component), and small $(\sim 10-20 \mathrm{~nm})$ granules of the same component are present on a pore (top-right region). The Y-Zr-oxide (blue and red components) are present at the triple-point, along with a small Fe contribution. The wrapping of the Zr-rich phase by the Y-Al phase is also again observed. 


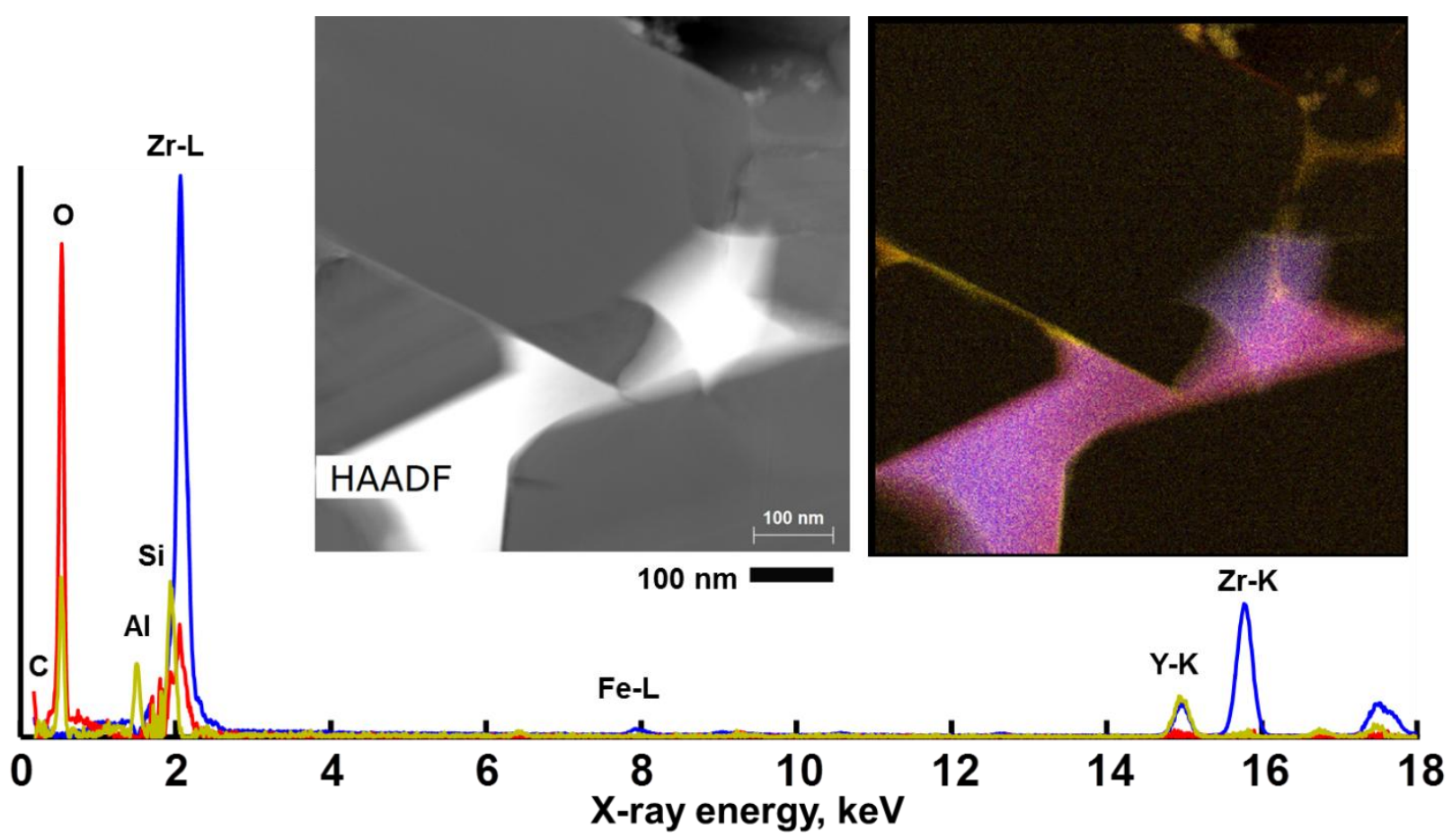

Figure 30: Higher magnification map of the corroded YZA-NITE. HAADF image and color overlay of the $\mathrm{Zr}$-O (blue), Al-Y-O (yellow), and O (red) component score images, along with associated loading spectra.

In summary, the YZA-NITE material showed significantly less macroscopic corrosion than the YA-NITE or CZA-2-NITE. Microscopically, this reduced corrosion manifests as reduced loss of the Y-Al-oxide phase at the grain boundaries and at some of the triple-points.

\section{Discussion}

For high purity CVD-SiC, corrosion under hydrothermal conditions tends to proceed somewhat uniformly, although the greater susceptibility of certain grain boundaries and stacking faults has been clearly shown to exist [33]. For TEP sintered SiC, the corrosion front proceeds in a particularly non-uniform fashion as shown in Figure 31. Simply, the microstructure consists of SiC grains inside an oxide matrix spreading between the grain boundaries and triple junctions. During hydrothermal corrosion, this oxide matrix dissolves faster than $\mathrm{SiC}$ grains, resulting in its selective recession. Since this oxide may act as the glue in the grain boundaries, selective dissolution may result in $\mathrm{SiC}$ grain fallout, before those grains themselves undergo dissolution.

Hydrothermal corrosion of high purity CVD-SiC is generally uniform, although grain boundaries and stacking faults respond with a higher rate of recession. For TEP SiC, the corrosion attack is shown by Figure 31. The grains are in an oxide matrix; since the oxide dissolves faster than the $\mathrm{SiC}$ grains, grain fallout occurs well before they can be corrosively attacked, resulting in a high material recession. 

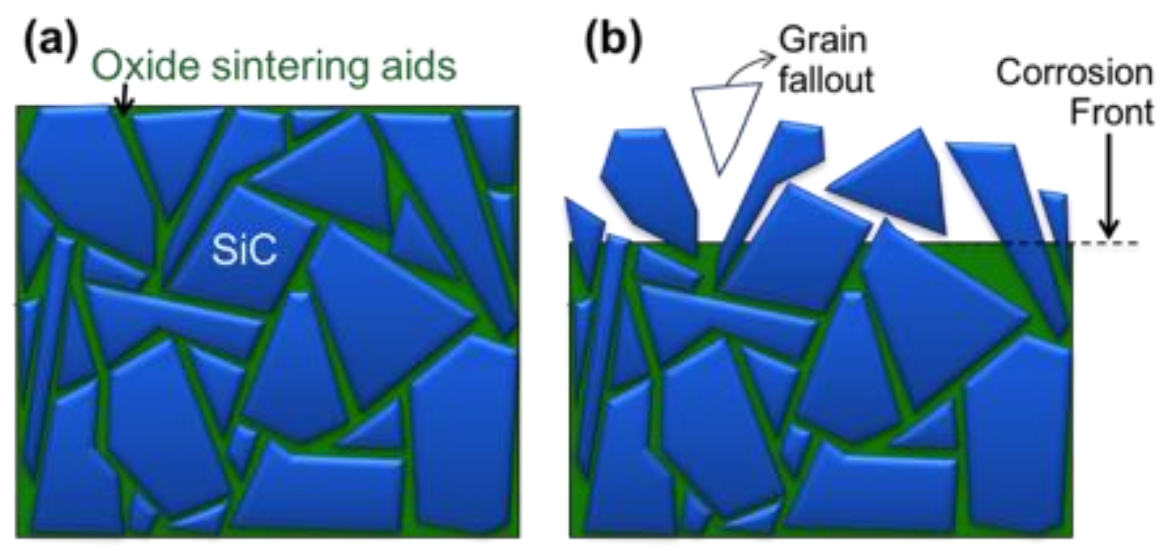

Figure 31. Simplified representation of (a) microstructure of sintered SiC consisting of blue SiC grains inside the green matrix representing the oxide sintering additives, and (b) selective corrosion of oxide sintering additives at the grain boundaries, resulting in faster dissolution of the matrix and SiC grain fallout.

The motivation behind incorporation of zirconia into the sintering additive system was to produce an oxide matrix that has comparable or even better dissolution resistance to $\mathrm{SiC}$. In this manner, the corrosion rate of sintered $\mathrm{SiC}$ could be reduced significantly to match that of high purity CVD-SiC. If the oxide matrix has even better corrosion resistance than $\mathrm{SiC}$, one might expect even slower dissolution rates.

The results showed that the macroscopic corrosion rates are: YA-NITE $\approx$ CZA-NITE $>$ YZANITE >> CVD-SiC. These trends are confirmed by the microscopic examination of the NITE-SiC variants. For the YA and CZA-2 NITE variants, the corrosion completely removes the Al cations from the material, leaving bare grain boundaries, and significant quantities of Fe-oxide were left behind on the stripped grain boundaries' surfaces. The degradation of the YZA-NITE was grossly similar, but all of the effects were less pronounced: specifically, some Al was retained in the Y-Al-oxide phase, and less Fe was observed coating the grain boundaries. Likely, the reduced Fe is due to less raw grain boundary surface being available rather than any inherent differences in the chemistry leading to Fe deposition. Unlike for the YZA variant where yttria was partly incorporated into the Zr-bearing oxides, ceria partitioned selectively and only with the Al-bearing oxide films at the grain boundaries. The subsequent dissolution of these films resulted in rapid corrosion of the material. In any case, for none the zirconia bearing NITE variants, the Zr-bearing oxide was uniformly distributed throughout the grain boundaries. Therefore, the strategy of producing an oxide matrix with comparable or better corrosion resistance than $\mathrm{SiC}$ did not succeed.

From the present results, it seems obvious that elimination of the alumina would provide improved corrosion behavior compared to the alumina-bearing grades. However, the problem is not that simple. Without at least a small amount of alumina (e.g., the $0.45 \%$ in CZA- and YZA-NITE here), the samples fail to sinter, achieving poor final density and significantly reduced mechanical and thermal properties. The $\sim 7 \times$ less alumina in the YZA-NITE appeared to improve the corrosion resistance compared to the YA-NITE, though the mass loss rate remained at least and order of magnitude higher than CVD-SiC. An important achievement of this present study is the fabrication of more corrosion tolerant NITE ceramics using oxide particular additives, which were not explored in previous works [21]. Obvious future explorations require more work in terms of obtaining good sintered densities in sintering systems with lower or no alumina contents. 
There is presently no knowledge of how neutron irradiation will affect hydrothermal corrosion of SiC or NITE-SiC. Recent ion-irradiation experiments showed significantly enhanced hydrothermal corrosion of SiC after irradiation [33], and hydrothermal corrosion experiments on CVD $\mathrm{SiC}$ and $\mathrm{SiC}_{\mathrm{m}} / \mathrm{SiC}_{\mathrm{f}}$ composites showed that there is always a driving force for $\mathrm{SiC} \rightarrow \mathrm{SiO} 2$ conversion and $\mathrm{SiO}_{2}$ dissolution in $\mathrm{LWR}$ environments [7, 30]. Ideally, further oxide-modification experiments may allow a balance between the superior corrosion resistance of CVD-SiC compared to NITE-SiC and the possibility of very poor corrosion resistance in irradiated SiC; irradiated zirconia, as an example, may have superior corrosion resistance to irradiated SiC matrix in NITE material. This, of course, is speculative, but is intended as an example of future directions necessary to balance properties vs. service conditions and sinterability.

Lastly, high-efficiency X-ray mapping, especially when coupled with MVSA data reduction and the good sensitivity to $\mathrm{C}$ and $\mathrm{O}$ of windowless SDD detectors, is a valuable tool for exploring corrosion behavior in the types of experiments shown here. The ability to map $\sim 5 \mu \mathrm{m} \times 5 \mu \mathrm{m}$ regions with $5 \mathrm{~nm}$ resolution, and determine the elements present at every triple point and grain boundary in an area containing dozens or hundreds of grains, makes an ensemble view of the preand post-corrosion structure fast and efficient to obtain, especially in comparison to the much smaller (and less representative) regions that could be interrogated without such instrumentation.

\section{Conclusions}

This work subjected three different NITE SiC ceramics (yttria-alumina, zirconia-ceriaalumina, and yttria-zirconia-alumina) to hydrothermal corrosion under PWR-like conditions. The yttria-alumina NITE fared poorly, consistent with prior observations. The zirconia-ceria-alumina sintering system was even worse at high ceria contents where the material disappeared altogether after two weeks of corrosion testing. At lower ceria and higher zirconia contents, this system performed similarly to the reference yttria-alumina sintered NITE-SiC. The yttria-zirconia-alumina system performed much better than the previous two; however, its mass loss rate still remained at least an order of magnitude larger than CVD-SiC. Corrosion was microscopically manifested by loss of grain-boundary oxide films, and deposition of Fe-O films (presumably from the corrosion apparatus). The yttria-alumina and zirconia-ceria-alumina alloys retained no aluminum cations in the structure after corrosion; the yttria-zirconia-alumina alloy did retain some aluminum cations, concomitant with the least amount of macroscopic corrosion. In the yttria-alumina NITE, the remaining post-corrosion yttria was observed to reform itself from polygonal triple-point pockets into large blocky rectangular shapes.

Reductions in the amount of alumina, insofar as the material can still be sintered, and seen to be needed to minimize corrosion. It seems likely that future refinements of the NITE sintering system to further reduce alumina content, and perhaps increase yttria or zirconia content or optimize their blending, may produce further improvements in hydrothermal corrosion properties of NITE-SiC.

\section{Acknowledgements}

The aid and technical insights of James Kiggans and Rachel Seibert during material preparation and characterization is gratefully acknowledged. The work presented in this paper was supported by the Advanced Fuels Campaign of the Fuel Cycle R\&D program in the Office of Nuclear Energy, US Department of Energy. This research was performed using instrumentation (FEI Talos 
F200X S/TEM) provided by the Department of Energy, Office of Nuclear Energy, Fuel Cycle R\&D Program and the Nuclear Science User Facilities.

\section{References}

[1] S.J. Zinkle, G. Was, Materials challenges in nuclear energy, Acta Materialia, 61 (2013) 735-758.

[2] S.J. Zinkle, K.A. Terrani, L.L. Snead, Is There a Role for Advanced Materials in Nuclear Energy Systems?, Current Opinion in Solid State and Materials Science, accepted (2016).

[3] S.J. Zinkle, K.A. Terrani, J.C. Gehin, L.J. Ott, L.L. Snead, Accident tolerant fuels for LWRs: A perspective, Journal of Nuclear Materials, 448 (2014) 374-379.

[4] Y. Katoh, L.L. Snead, C. Henager, T. Nozawa, T. Hinoki, A. Iveković, S. Novak, S.G. de Vicente, Current status and recent research achievements in $\mathrm{SiC} / \mathrm{SiC}$ composites, Journal of Nuclear Materials, 455 (2014) 387-397.

[5] Y. Katoh, L.L. Snead, I. Szlufarska, W.J. Weber, Radiation effects in SiC for nuclear structural applications, Current Opinion in Solid State and Materials Science, 16 (2012) 143-152.

[6] E.J. Opila, R.E. Hann, Paralinear oxidation of CVD SiC in water vapor, Journal of The American Ceramic Society, 80 (1997) 197-205.

[7] K.A. Terrani, B.A. Pint, C.M. Parish, C.M. Silva, L.L. Snead, Y. Katoh, Silicon Carbide Oxidation in Steam up to $2 \mathrm{MPa}$, Journal of the American Ceramic Society, 97 (2014) 2331-2352.

[8] K. Yueh, D. Carpenter, H. Feinroth, Clad in clay, Nuclear Engineering International, 55 (2010) 1416.

[9] D.M. Carpenter, An assessment of silicon carbide as a cladding material for light water reactors, in, Massachusetts Institute of Technology, 2010.

[10] C. Deck, H. Khalifa, B. Sammuli, T. Hilsabeck, C. Back, Fabrication of SiC-SiC composites for fuel cladding in advanced reactor designs, Progress in Nuclear Energy, 57 (2012) 38-45.

[11] H. Kishimoto, T. Shibayama, Y. Asakura, D. Hayasaka, Y. Kohno, A. Kohyama, Sic/Sic Fuel Cladding by Nite Process for Innovative LWR-Concept and Process Development of Fuel Pin Assembly Technologies, Ceramics for Environmental and Energy Applications II: Ceramic Transactions, Volume 246, (2014) 93-98.

[12] H.K. Naofiimi Nakazato, Y. Kohno, A. Kohyamal, SiC/SiC Fuel Cladding by NITE process for Innovative LWR-Cladding forming process development, Ceramics for Environmental and Energy Applications II: Ceramic Transactions, 246 (2014) 109.

[13] L.L. Snead, K.A. Terrani, F. Venneri, Y. Kim, J.E. Tulenko, C.W. Forsberg, P.F. Peterson, E.J. Lahoda, Fully Ceramic Microencapsulated Fuels: A Transformational Technology for Present and Next Generation Reactors-Properties and Fabrication of FCM Fuel, Transactions of the American Nuclear Society, 104 (2011).

[14] K.A. Terrani, L.L. Snead, J.C. Gehin, Microencapsulated fuel technology for commercial light water and advanced reactor application, Journal of Nuclear Materials, 427 (2012) 209-224.

[15] S. Dong, Y. Katoh, A. Kohyama, Development of unidirectional SiC/SiC composites by hot pressing using carbon-coated Tyranno-SA fiber, in: Ceramic Engineering and Science Proceedings, American Ceramic Society, Westerville, OH, 2002, pp. in press.

[16] H. Kishimoto, K. Ozawa, O. Hashitomi, A. Kohyama, Microstructural evolution analysis of NITE $\mathrm{SiC} / \mathrm{SiC}$ composite using TEM examination and dual-ion irradiation, Journal of Nuclear Materials, 367 (2007) 748-752.

[17] K.A. Terrani, J.O. Kiggans, Y. Katoh, K. Shimoda, F.C. Montgomery, B.L. Armstrong, C.M. Parish, J.D. Hunn, L.L. Snead, Fabrication and characterization of fully ceramic microencapsulated fuels, Journal of Nuclear Materials, 426 (2012) 268-276. 
[18] T. Koyanagi, S. Kondo, T. Hinoki, Effect of differential swelling between fiber and matrix on the strength of irradiated SiC/SiC composites, Journal of Nuclear Materials, 442 (2013) S380-S383.

[19] M. Omori, H. Takei, Pressureless sintering of SiC, Journal of The American Ceramic Society, 65 (1982).

[20] L.S. Sigl, Thermal conductivity of liquid phase sintered silicon carbide, Journal of the European Ceramic Society, 23 (2003) 1115-1122.

[21] F. Rodríguez-Rojas, A. Ortiz, F. Guiberteau, M. Nygren, Oxidation behaviour of pressureless liquid-phase-sintered $\alpha$-SiC with additions of 5Al $203+3 \mathrm{RE} 203$ (RE= La, Nd, Y, Er, Tm, or Yb), Journal of the European Ceramic Society, 30 (2010) 3209-3217.

[22] K.A. Terrani, J. Kiggans, C.M. Silva, C. Shih, Y. Katoh, L.L. Snead, Progress on matrix SiC processing and properties for fully ceramic microencapsulated fuel form, Journal of Nuclear Materials, 457 (2015) 9-17.

[23] K.A. Terrani, J.O. Kiggans, Y. Katoh, K. Shimoda, F.C. Montgomery, B.L. Armstrong, C.M. Parish, T. Hinoki, J.D. Hunn, L.L. Snead, Fabrication and characterization of fully ceramic microencapsulated fuels, Journal of Nuclear Materials, 426 (2012) 268-276.

[24] C. Ang, T. Koyanagi, K. Terrani, C. Shih, J. Kiggans, L. Snead, Y. Katoh, Microstructure, thermal and mechanical properties of neutron irradiated monolithic $\mathrm{SiC}$ fabricated by transient eutectic phase sintering, submitted to Journal of Nuclear Materials, (2017).

[25] Y. Katoh, K.A. Terrani, Systematic Technology Evaluation Program for SiC/SiC Compositebased Accident-Tolerant LWR Fuel Cladding and Core Structures: Revision 2015, ORNL/TM2015/454, Oak Ridge National Laboratory (ORNL), 2015.

[26] W.-J. Kim, D. Kim, J.Y. Park, Fabrication and material issues for the application of SiC composites to LWR fuel cladding, Nuclear Engineering and Technology, 45 (2013) 565-572.

[27] W.-J. Kim, H.S. Hwang, J.Y. Park, W.-S. Ryu, Corrosion behaviors of sintered and chemically vapor deposited silicon carbide ceramics in water at 360 C, Journal of Materials Science Letters 22 (2003) 581-584.

[28] W.J. Kim, H.S. Hwang, J.Y. Park, Corrosion behavior of reaction-bonded silicon carbide ceramics in high-temperature water, Journal of materials science letters, 21 (2002) 733-735.

[29] H. Hirayama, T. Kawakubo, A. Goto, T. Kaneko, Corrosion behavior of silicon carbide in $290 \mathrm{C}$ water, Journal of The American Ceramic Society, 72 (2005) 2049-2053.

[30] K.A. Terrani, Y. Yang, Y.-J. Kim, R. Rebak, H. Meyer, T.J. Gerczak, Hydrothermal corrosion of SiC in LWR coolant environments in the absence of irradiation, Journal of Nuclear Materials, 465 (2015) 488-498.

[31] D. Kim, H.-G. Lee, J.Y. Park, J.-Y. Park, W.-J. Kim, Effect of dissolved hydrogen on the corrosion behavior of chemically vapor deposited $\mathrm{SiC}$ in a simulated pressurized water

reactor environment, Corrosion science, 98 (2015) 304-309.

[32] J.-Y. Park, I.-H. Kim, Y.-I. Jung, H.-G. Kim, D.-J. Park, W.-J. Kim, Long-term corrosion behavior of $\mathrm{CVD} \mathrm{SiC} \mathrm{in} 360^{\circ} \mathrm{C}$ water and $400^{\circ} \mathrm{C}$ steam, Journal of Nuclear Materials, 443 (2013) 603-607.

[33] S. Kondo, M. Lee, T. Hinoki, Y. Hyodo, F. Kano, Effect of Irradiation Damage on Hydrothermal Corrosion of SiC, Journal of Nuclear Materials, 464 (2015) 36-42.

[34] K.E. Sickafus, L. Minervini, R.W. Grimes, J.A. Valdez, M. Ishimaru, F. Li, K.J. McClellan, T. Hartmann, Radiation tolerance of complex oxides, Science, 289 (2000) 748-751.

[35] S. Lawson, Environmental degradation of zirconia ceramics, Journal of the European Ceramic Society, 15 (1995) 485-502.

[36] F. Clinard, D. Rohr, W. Ranken, Neutron-Irradiation Damage in Stabilized ZrO2, Journal of The American Ceramic Society, 60 (1977) 287-288.

[37] R. Ball, M. Mignanelli, T. Barry, J. Gisby, The calculation of phase equilibria of oxide coreconcrete systems, Journal of Nuclear Materials, 201 (1993) 238-249. 
[38] O. Fabrichnaya, C. Wang, M. Zinkevich, F. Aldinger, C. Levi, Phase equilibria and thermodynamic properties of the ZrO2-Gd01. 5-Y01. 5 system, Journal of phase equilibria and diffusion, 26 (2005) 591-604.

[39] S. Huang, L. Li, J. Vleugels, P. Wang, O. Van der Biest, Thermodynamic prediction of the nonstoichiometric phase $\mathrm{Zr} 1-\mathrm{z}$ Ce z $\mathrm{O} 2-\mathrm{x}$ in the $\mathrm{ZrO} 2-\mathrm{CeO} 1.5-\mathrm{CeO} 2$ system, Journal of the European Ceramic Society, 23 (2003) 99-106.

[40] C.M. Parish, N.K. Kumar, L.L. Snead, P.D. Edmondson, K.G. Field, C. Silva, A.M. Williams, K. Linton, K.J. Leonard, LAMDA: Irradiated-Materials Microscopy at Oak Ridge National Laboratory, Microscopy and Microanalysis, 21 (2015) 1003-1004.

[41] C.M. Parish, MT3FT-150R0204122: Report on the acquisition and installation of FEI Talos F200X S/TEM, Oak Ridge National Laboratory (ORNL), Oak Ridge, TN (United States), 2015. http://www.osti.gov/servlets/purl/1234344/.

[42] C.M. Parish, M.K. Miller, A review of advantages of high-efficiency X-ray spectrum imaging for analysis of nanostructured ferritic alloys, Journal of Nuclear Materials, 462 (2015) 433-442.

[43] C.M. Parish, Multivariate Statistics Applications in Scanning Transmission Electron Microscopy X-Ray Spectrum Imaging, in: P.W. Hawkes (Ed.) Advances in Imaging and Electron Physics, Vol 168, 2011, pp. 249-295.

[44] P.G. Kotula, M.R. Keenan, J.R. Michael, Automated analysis of SEM X-ray spectral images: a powerful new microanalysis tool, Microscopy and Microanalysis, 9 (2003) 1-17.

[45] M.R. Keenan, P.G. Kotula, Accounting for Poisson noise in the multivariate analysis of ToF-SIMS spectrum images, Surface and Interface Analysis, 36 (2004) 203-212.

[46] M.R. Keenan, P.G. Kotula, Optimal scaling of TOF-SIMS spectrum-images prior to multivariate statistical analysis, Applied Surface Science, 231-232 (2004) 240-244.

[47] M.H. Van Benthem, M.R. Keenan, D.M. Haaland, Aplication of equality constraints on variables during alternating least squares procedures, Journal of Chemometrics, 16 (2002) 613-622.

[48] M.H. Van Benthem, M.R. Keenan, Fast algorithm for the solution of large-scale non-negativityconstrained least squares problems, Journal of Chemometrics, 18 (2004) 441-450.

[49] V.S. Smentkowski, S.G. Ostrowski, M.R. Keenan, A comparison of multivariate statistical analysis protocols for ToF-SIMS spectral images, Surface and Interface Analysis, 41 (2009) 88-96.

[50] M.R. Keenan, Exploiting Spatial-Domain Simplicity in Spectral Image Analysis, Surface and Interface Analysis, 41 (2009) 79-87.

[51] P.G. Kotula, M.R. Keenan, Automated analysis of large ( $>4 \mathrm{~Gb}$ ) spectral images with efficient out-of-core-RAM algorithms, Microscopy and Microanalysis, 9 (2003) 152-153. 